\title{
Risk of malignancy in patients with Inflammatory Bowel Disease treated with Azathioprine or 6-Mercaptopurine: The Cape Town experience.
}

\author{
By Mashiko Setshedi
}

STSMASO01

Submitted to the University of Cape Town in partial fulfilment of the requirements for the Master of Public Health degree

Faculty of Health Sciences

\section{UNIVERSITY OF CAPE TOWN}

February 2008

\author{
Supervisors: \\ Dr Landon Myer \\ School of Public Health \& Family Medicine \\ University of Cape Town \\ Dr Gill Watermeyer \\ Gastroenterology Department \\ Groote Schuur Hospital \\ Cape Town
}


The copyright of this thesis vests in the author. No quotation from it or information derived from it is to be published without full acknowledgement of the source. The thesis is to be used for private study or noncommercial research purposes only.

Published by the University of Cape Town (UCT) in terms of the non-exclusive license granted to UCT by the author. 


\section{Declaration}

I, Mashiko Setshedi, hereby declare that the work on which this dissertation is based is my original work (except where acknowledgements indicate otherwise) and that neither the whole work nor any part of it has been, is being, or is to be submitted for another degree in this or any other university.

I empower the university to reproduce for the purposes of research either the whole or any portions of the contents in any manner whatsoever.

Signature

Date:

Place: 


\section{Acknowledgements}

I would like to thank my supervisors for their guidance and particularly their patience throughout the process of completing this work. Specifically I am grateful to Dr Watermeyer for the idea to do this project and her invaluable clinical insights, and Dr Myer for his statistical and epidemiological prowess. This work could not have been completed without their input.

I would also like to acknowledge Dr Trevor Winter who commissioned the dataset from which this study and other studies in the GIT clinic emanate and Dr David Epstein for continually updating the dataset and for his advice.

Finally I would like to thank my mother, Quinn Setshedi who is my pillar of strength and constant source of inspiration. 


\section{Abstract}

The benefits of the use of Azathioprine (AZA) and its metabolite 6-mercaptopurine (6-MP) in the treatment of Inflammatory Bowel Disease (IBD) are well established. However concern regarding the long-term use of these agents in the induction of certain malignancies particularly lymphoma and skin cancer has been reported in renal transplant and rheumatoid arthritis patients. In IBD patients however, several retrospective and prospective studies have been conducted (including two meta-analyses) with divergent results.

The primary objective of this study was to compare the incidence of cancer in IBD patients treated with AZA/6MP with those not treated. Secondary objectives were to assess if skin cancer had a higher incidence of occurrence than other cancers, and to determine the independent risk factors associated with developing any malignancy.

A retrospective cohort study based on clinical and pathology records of patients attending the IBD clinic at Groote Schuur Hospital from 1960 to 2007 was conducted. Records were reviewed for: patient demographic characteristics, the nature and extent of the disease, the duration of treatment with AZA/6MP and the development and type of malignancy. Data on the use of AZA or 6MP was grouped into the "treatment" group, whilst those not treated with these agents were classified as the "no treatment' group. A third group was defined; these were patients in whom data on immunosuppression was either missing or inconsistent. These patients were referred to as the group "of unknown treatment status".

The records of 1084 patients were analysed. The median age of the cohort was 33 (IQR 25-46) at the last follow-up and the median age at diagnosis of IBD was 34 . The majority of the cohort $(61 \%)$ was female. The median years of IBD follow-up was 9 (IQR $3.3-18.4$ ). A total of $836(77 \%)$ patients have never been treated with AZA 6 MP, while $123(11.5 \%)$ used either AZA or 6MP or both. Treatment data was unavailable for $11.5 \%$ of the cohort. There were a total of 49 cancers ( $4.5 \%$ of the cohort) identified. CRC (15 cancers) was the commonest, followed by skin cancer ( 7 cases). Non-Hodgkin's Iymphoma (NHL) was seen in 5 patients. Overall $4 \%$ of patients receiving AZA/6MP developed a cancer $(n=5)$ compared to $4.8 \%$ in the "no treatment" arm $(n=40), p=0.725$ and $3.2 \%$ of patients in the group of "unknown treatment status" $(n=4), p=0.716$.

The incidence of CRC and NHL in the treated versus untreated group was not statistically significant ( $p=0.211$ and 0.536 respectively); skin cancers however were twice more common (IRR $=2.4$ ), among patients receiving $A Z A$ or $6 M P$, however this was not statistically significant $(p=0.333)$. In a logistic regression model including age, gender, type of IBD, disease extent, and use of AZA or 6MP 
the relative odds of cancer were independently associated with age, $O R=1.04$ $(95 \% \mathrm{Cl}, 1.04-1.07 ; p=0.000)$ and the age at IBD diagnosis, OR: $1.04(95 \% \mathrm{Cl}$, $1.03-1.07 ; p=0.000$ ).

This large series showed no difference in the incidence of cancer overall in those treated with AZA/6MP and those not treated. However, although not statistically significant this study also showed an increased risk of skin cancer in IBD patients treated with thiopurines. This increased risk was influenced by the age of the patient and the age at IBD diagnosis. 


\section{Contents}

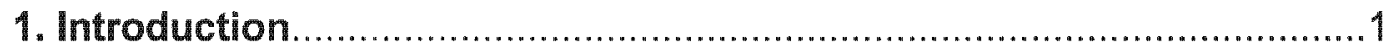

1.1. Aims and objectives ..............................................................

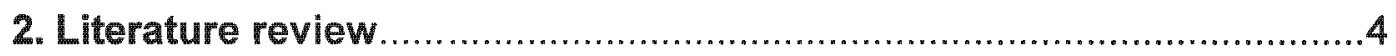

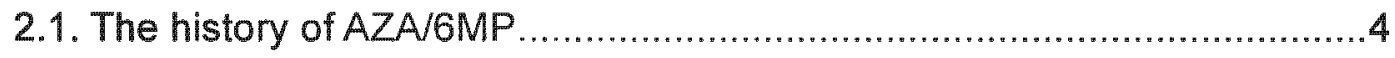

2.2. Potential mechanisms for inducing skin cancer.................................5

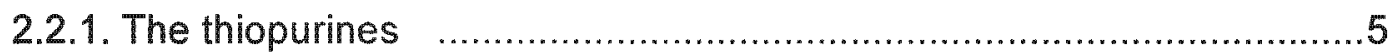

2.2.1.1. Photosynthesisers ........................................................... 5

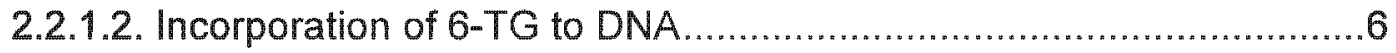

2.2.1.3. Increased levels of sister chromatid exchanges (SCE's) ................6

2.3. The efficacy of AZA/GMP in UC/CD ..........................................

2.3.1. Mechanism of action of AZAV6MP ........................................... 8

2.4. Data from renal transplant/rheumatoid arthritis patients........................8

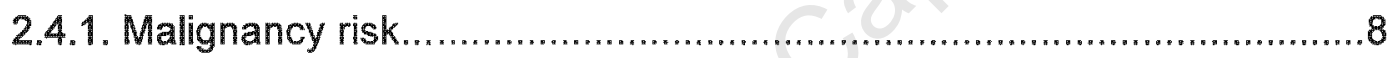

2.4.1.1. Renal transplantation........................................................ 8

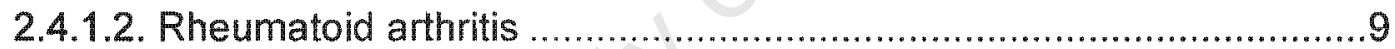

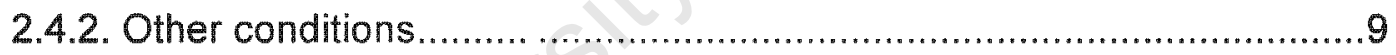

2.5. Data in the general IBD population........................................... 10

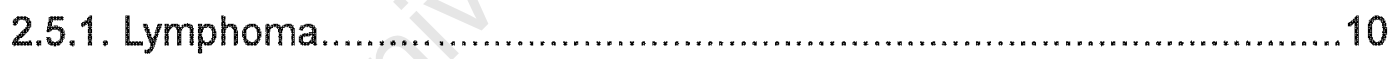

2.5.2. Small bowel cancers in IBD .................................................. 11

2.5.2.1. Small bowel cancer in $\mathrm{CD}$................................................ 11

2.5.2.2. Small bowel cancer in UC ................................................. 11

2.5.3. Colorectal cancer and IBD ................................................ 12

2.5.3.1. Colorectal cancer in CD .................................................. 12

2.5.3.2. Colorectal cancer in UC................................................. 13

2.5.4. Gastric carcinoma .......................................................... 14

2.5.5. Cholangiocarcinoma and PSC ............................................. 14 


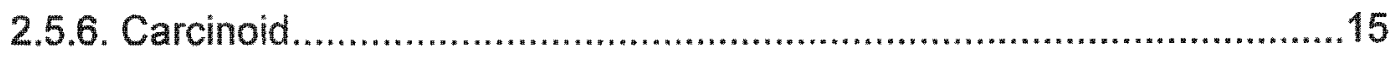

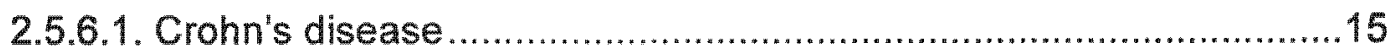

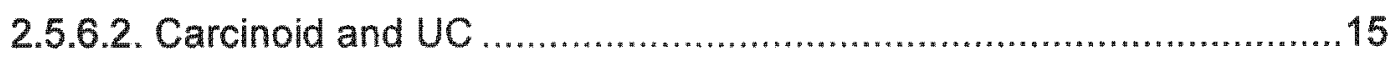

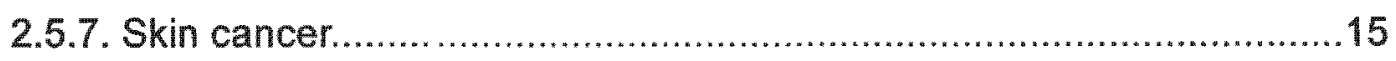

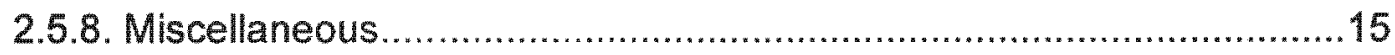

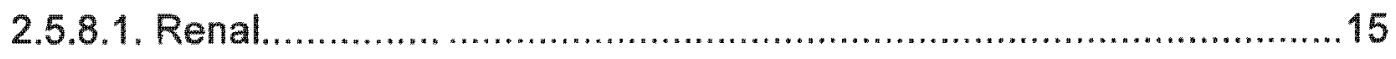

2. 6. Data in IBD patients on immunosuppression ..................................15

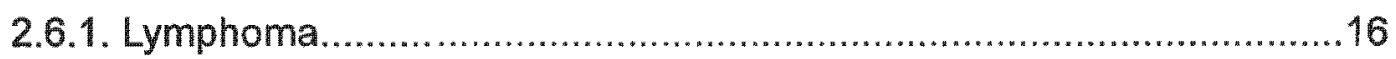

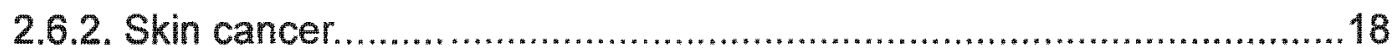

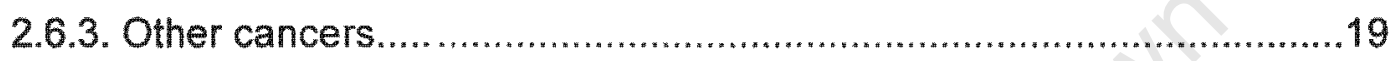

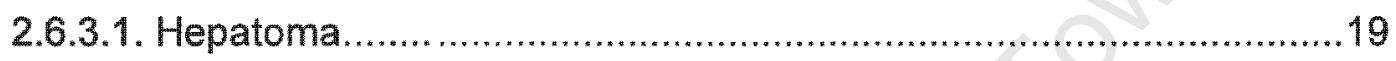

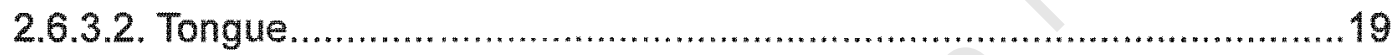

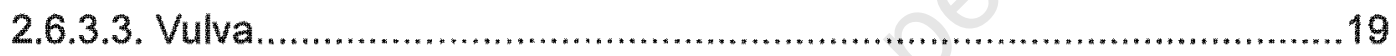

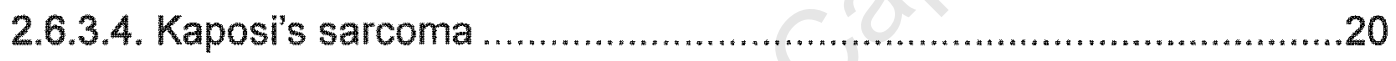

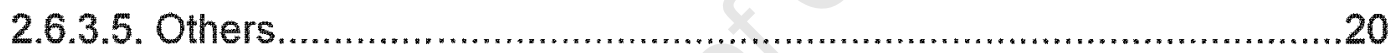

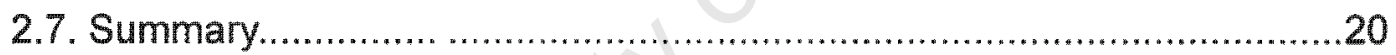

3. Materials and methods

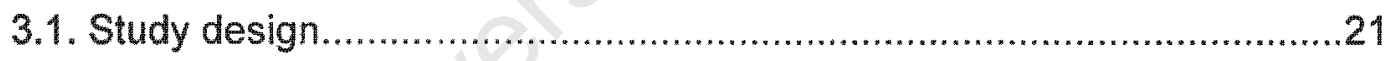

3.2. The database

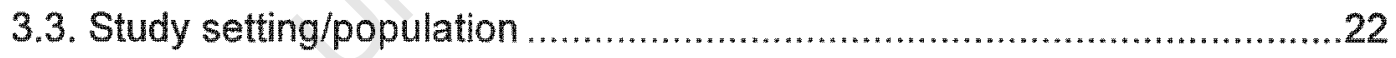

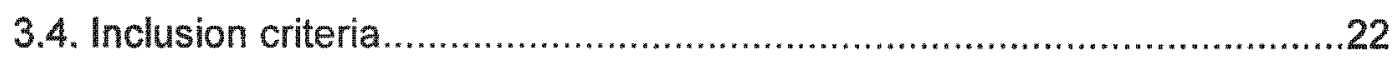

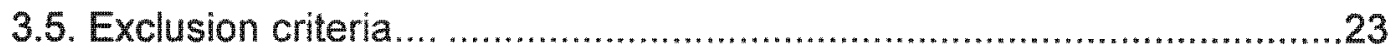

3.6. Definition of terms/measurements .....................................................23

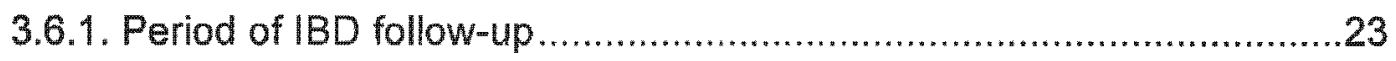

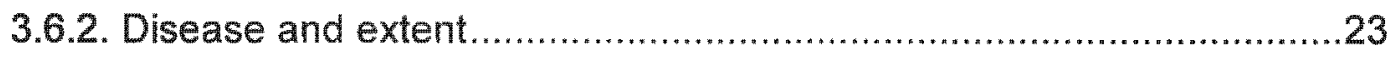

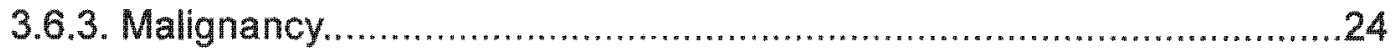

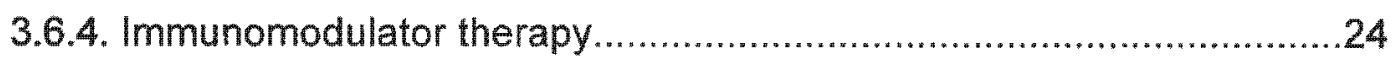




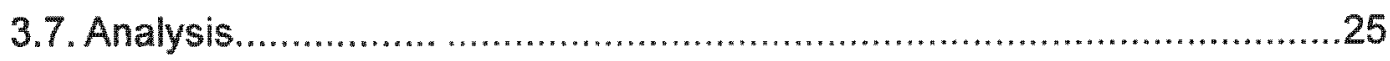

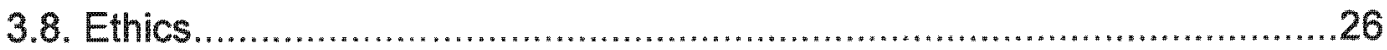

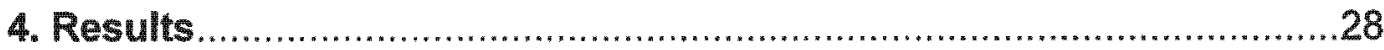

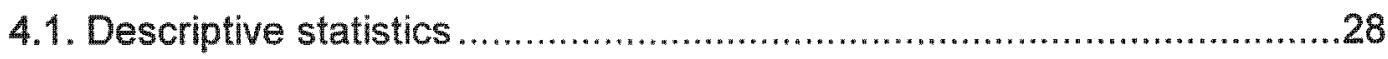

4.1.1. Patient demographic characteristics...............................................28

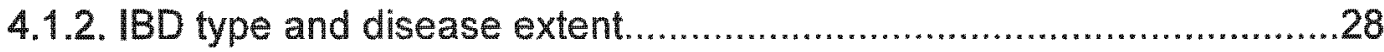

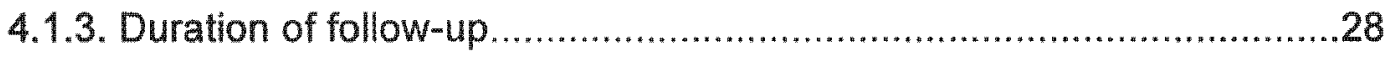

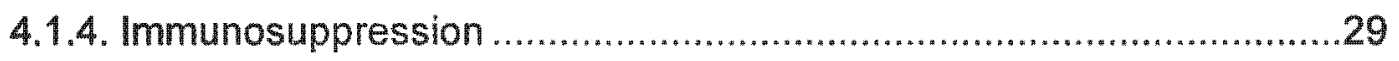

4.1.4.1. Duration and dose of therapy with immunosuppression ..................30

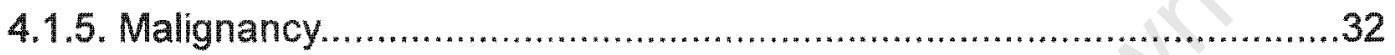

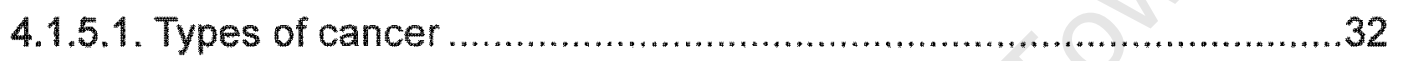

4.2. Bivariate analysis for predicting immunosuppression.............................33

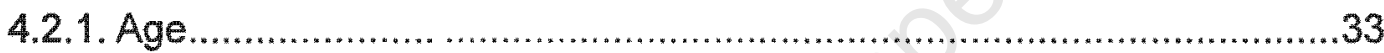

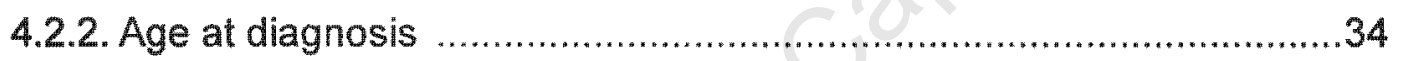

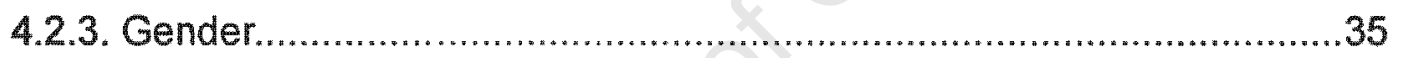

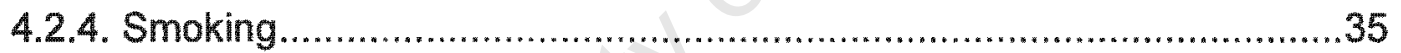

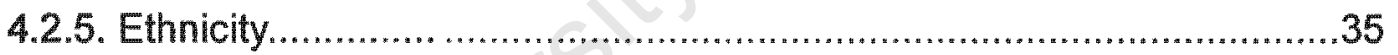

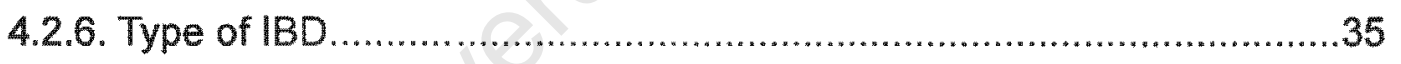

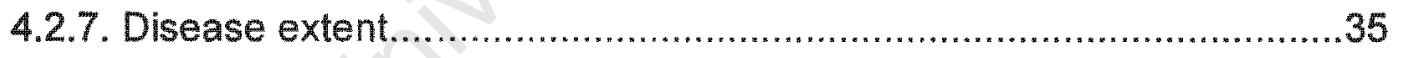

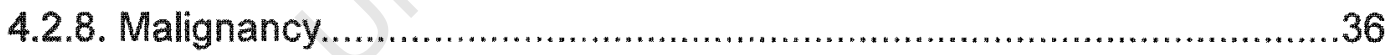

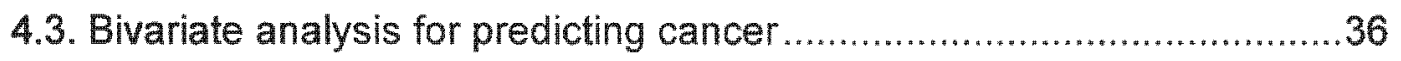

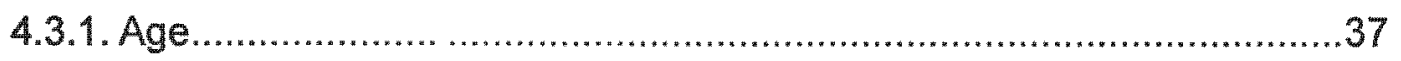

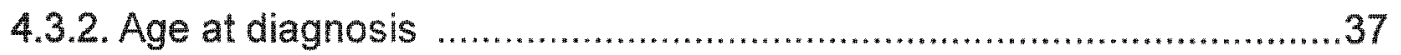

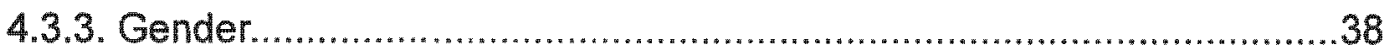

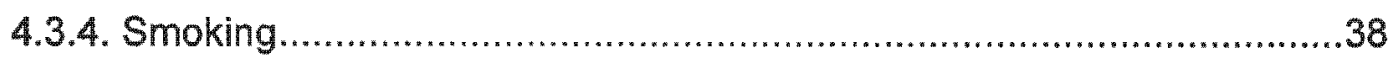

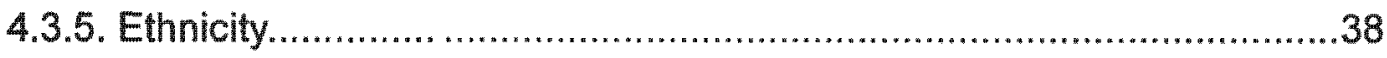

4.3.6. IBD type and disease extent .......................................................39 


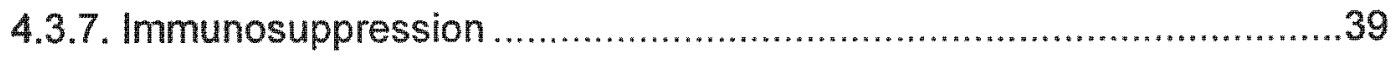

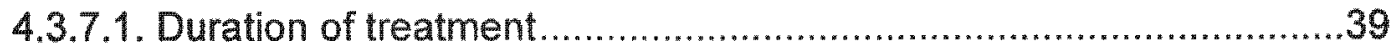

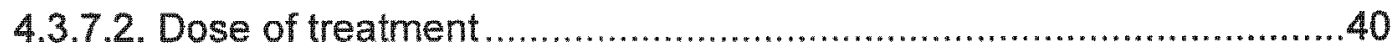

4.4. Survival estimates of the groups …....................................................4

4.5. Models of the relative hazard of cancer during follow-up ......................43

4.5.1. Unadjusted odds ratios for prediction of cancer ................................43

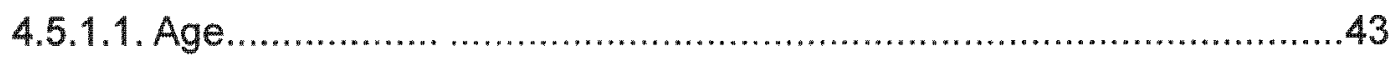

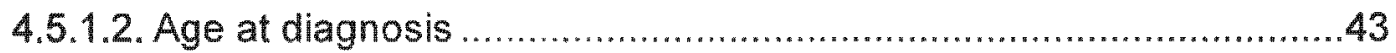

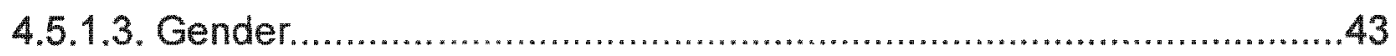

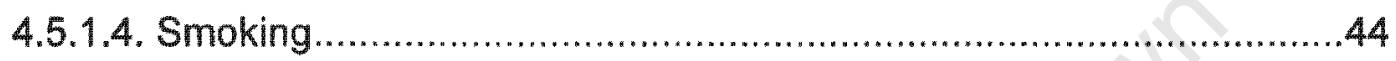

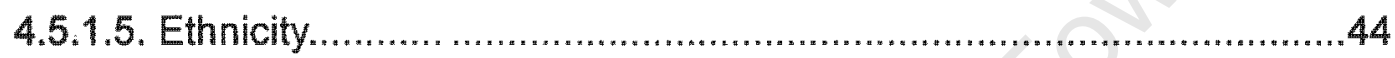

4.5.1.6. IBD and disease extent ............................................................44

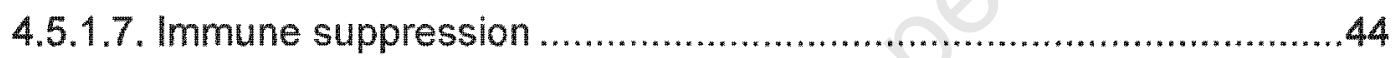

4.5.2. Adjusted odds ratios for prediction of cancer .....................................45

4.6. Models of the relative odds of receiving immunosuppression ................46

4.6.1. Unadjusted odds ratios for prediction of immunosuppression.............46

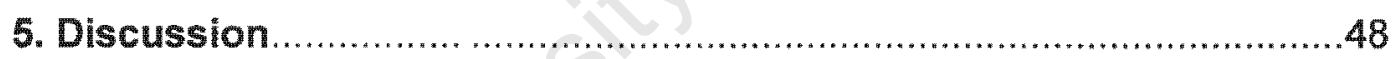

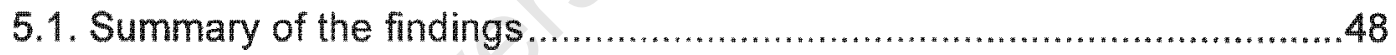

5.2. Potential reasons for the findings...................................................48

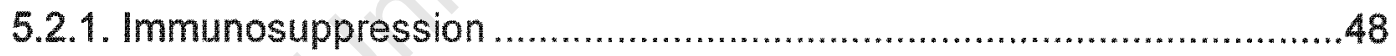

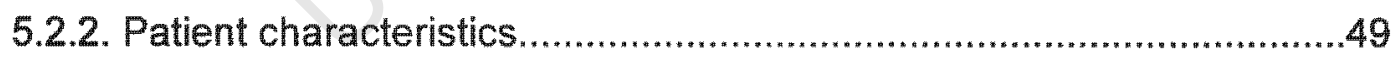

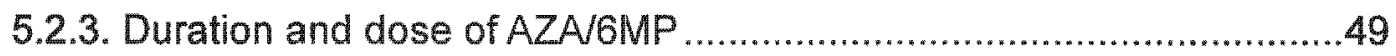

5.2.4. Small number/ insufficient power....................................................50

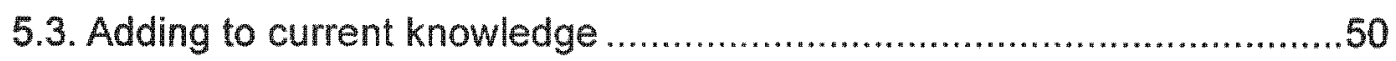

5.4. Differences and similarities with other studies.....................................51

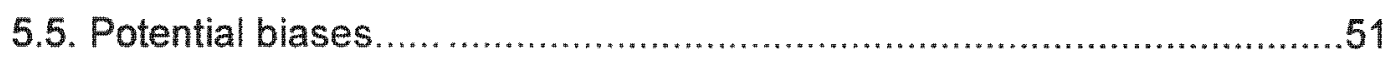

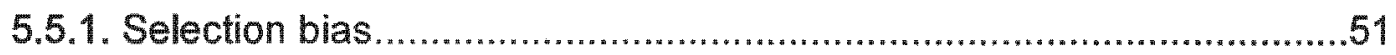

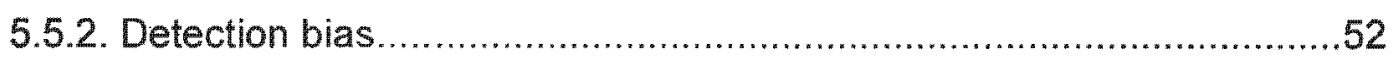

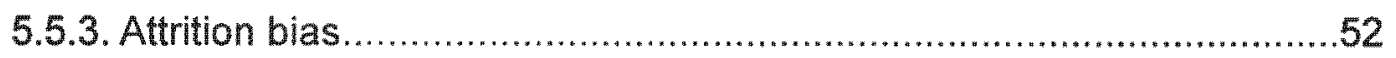

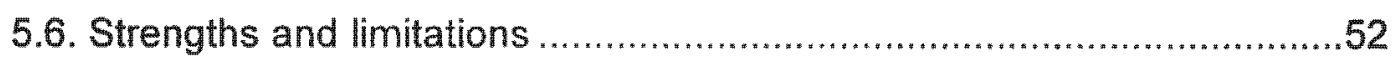




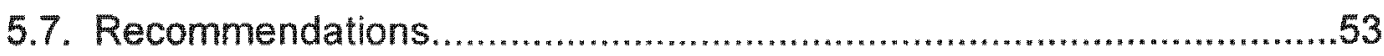

5.8 . Influence on policy ................................................................... 53

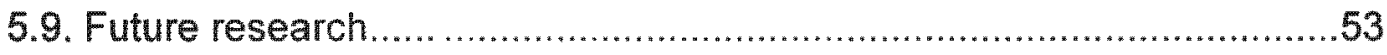

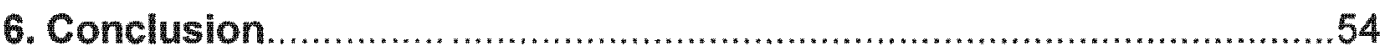

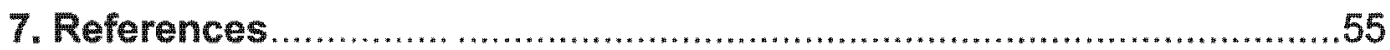

8. Appendices A \& B: ...............................................................64

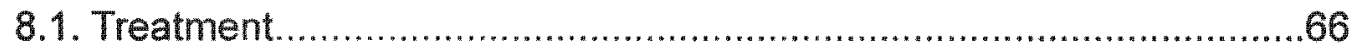

8.1.1. Cox-snell residuals.........................................................66 66

8.1.2. Martingale residuals.....................................................67

8.1.3. Deviance residuals........................................................67

8.1.4. Proportional hazards assumption...........................................68

8.2. Summary ...........................................................................69 


\section{Table Of Figures}

Fig 1: Inclusion and exclusion of the cohort.............................................29

Fig 2: Age stratified by treatment.............................................................

Fig 3: Age at diagnosis stratified by treatment........................................... 34

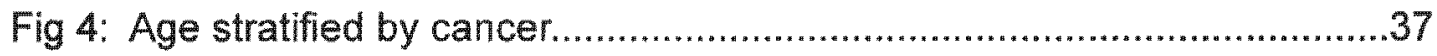

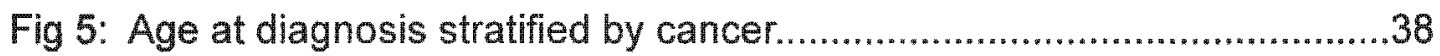

Fig 6: Median duration of AZA (months) stratified by cancer...........................39

Fig 7: Median dose of AZAV6MP (months) stratified by cancer......................40

Fig 8: Cancer-mfree survival curves for all cancer in the 3 treatment groups.....41

Fig 9: Cancer-free survival curves for CRC in the 3 treatment groups...........41

Fig10: Cancer-free survival curves for NHL in the 3 treatment groups.............42

Fig 11 :Survival curves for skin cancer in the 3 treatment groups...................42 


\section{Tables}

Table 1: Demographic characteristics of subjects, overall and stratified by treatment status.

Table 2: $\quad$ Types of cancer (of interest) stratified by treatment status.

Table 3: $\quad$ Types of other miscellaneous cancer in the cohort stratified by treatment status. 33

Table 4: Comparison of patients with and without cancer. 36

Table 5: $\quad$ Unadjusted odds ratios for individual predictors of cancer.

Table 6: Various models for predicting cancer (adjusted). .46

Table 7: Unadjusted odds ratios for individual predictors of immunosuppression 


\section{Abbreviations}

$\begin{array}{ll}\text { GMP } & \text { 6-mercaptopurine } \\ \text { AZA } & \text { Azathioprine } \\ \text { BCC } & \text { Basal Cell Carcinoma } \\ \text { CD } & \text { Crohn's Disease } \\ \text { Cl } & \text { Confidence Interval } \\ \text { CNS } & \text { Central nervous system } \\ \text { CRC } & \text { Colorectal carcinoma } \\ \text { CSA } & \text { Cyclosporin A } \\ \text { DNA } & \text { Deoxyribonucleic Acid } \\ \text { EBV } & \text { Ebstein Barr Virus } \\ \text { GI } & \text { Gastro-intestinal } \\ \text { GIT } & \text { Gastro-intestinal Tract } \\ \text { IARC } & \text { International Agency for Research on Cancer } \\ \text { IBD } & \text { Inflammatory Bowel Disease } \\ \text { IC } & \text { Indeterminate Colitis } \\ \text { IQR } & \text { Inter-quartile range } \\ \text { IRR } & \text { Incident Rate Ratio } \\ \text { MTX } & \text { Methotrexate } \\ \text { NHL } & \text { Non-Hodgkin's Lymphoma } \\ \text { Nm } & \text { Nanometers } \\ \text { PSC } & \text { Primary Sclerosing Cholangitis } \\ \text { RR } & \text { Risk Ratio } \\ \text { SCC } & \text { Squamous Cell Carcinoma } \\ \text { SIR } & \text { Standardised Incidence ratio } \\ \text { SMR } & \text { Standardised Mortality Ratio } \\ \text { UC } & \text { Ulceratice Colitis } \\ \text { UK } & \text { United Kingdom } \\ \text { UV } & \text { Ultelet }\end{array}$




\section{Introduction}

Idiopathic inflammatory bowel disease (IBD) comprises those conditions characterized by a tendency for chronic or relapsing immune activation and inflammation within the gastrointestinal tract (Sleisenger and Fordtran's $8^{\text {th }}$ edition). Crohn's disease (CD) and ulcerative colitis (UC) are the two major forms (prototype) of IBD. UC is a non-transmural disease (not all the layers of the gastrointestinal are affected, with inflammation limited to the mucosa and submucosa) and is restricted to the colon. CD in contrast results in inflammation of all the layers of the gut, and can affect any part from the mouth to the anus (Daniel et al., 2007). Although the two conditions share many similarities (epidemiology, pathogenesis) they have some differences too. The diagnosis of UC and CD is made by using clinical (history and physical examination), biochemical, endoscopic, radiologic and histological criteria (Daniel et al., 2002) and can thus be differentiated from one another. Nevertheless, it can be difficult in some cases to diagnose with certainty either UC or CD as patients may have a similar clinical presentation, similar biochemical changes and the lack of specific diagnostic features on a histological specimen. Similarly while there is some overlap in the management of these two conditions, some aspects of management vary considerably as does the natural history.

Due to the fact that IBD is incurable, the primary goals of therapy, therefore, are to firstly induce a clinical remission, and secondly to maintain this remission over a prolonged period of time. The latter ensures the maintenance of the patient's quality of life by reducing the number of acute flares of disease, restoration of the nutritional status, prevention of complications of the disease and the optimum timing for surgical therapy (Katz et al., 2007). The ultimate aim therefore is to minimise the morbidity associated with these diseases.

A remission can be achieved with a combination of drugs employing a stepwise approach where less potent but safer medications for the milder forms of disease are used initially, and treatment escalated as is required as the disease progresses (Katz et al., 2007). In general, patients are initially treated with aminosalicylates and antibiotics, followed by corticosteroids and immunomodulators for the more severe forms of disease, and finally biologic agents such as infliximab and/or surgical procedures if the disease proves refractory. The majority of patients with 
UC and CD can be managed successfully using aminosalicylates, antibiotics and corticosteroids, alone or in combination. In those with more severe forms of disease resistant to the initial therapy and in those who have recurrent disease flares, immunomodulating agents are used. These immunomodulating agents have become an integral part of the pharmacologic armamentarium for the treatment of IBD (Kwon et al., 2005).

Immunomodulating agents work by suppressing the immune response and have been used in the treatment of many immunological disorders. Some of the commonly used immunomodulators are azathioprine (AZA), its metabolite 6-mercaptopurine (6MP), cyclosporine (CSA), methotrexate (MTX) and tacrolimus to name but a few. More recently have been the addition of potent biologic agents, 2 of which (Infliximab and Adalimumab) are registered for use in IBD and appear to be changing the face of treatment for these chronic conditions, however, the two most commonly used immunomodulating drugs for IBD are AZA and 6MP (Kwon et al., 2005). These drugs collectively referred to as thiopurines, have been used for the treatment of IBD since the 1960's (Fraser et al., 2002). The thiopurines are prodrugs which culminate in the formation of thioguanines which are the precursors of nucleic acid synthesis. Both these drugs have been proven to be effective in both inducing (in the acute setting) and maintaining remission of both UC and CD (Cochrane systematic reviews 2000; Fraser et al., 2002). They can be administered orally and compared to the other immunomodulating agents have fewer side effects. They have a slow onset of action due to a long half life and thus may take about 4 months to have an effect (Katz et al., 2007). This delay in action allows for combination therapy with other groups of drugs (for instance, they can be introduced during the dose-reducing phase of steroid therapy), but once started AZA and 6MP have a prolonged therapeutic effect which is maintained for several years (Katz et al., 2007).

It is not known whether AZA and 6MP can or should be withdrawn in patients who have achieved long-term remission of their disease, but it appears that many clinicians discontinue treatment after about 5 years of use (Lamers et al., 1999). The reasons for these are not explicitly stated; however, this practice may be due to covert concern about the long-term safety of the drugs, particularly, with reference to the reported potential of these drugs to induce malignancies. 
Initially, concern regarding the long-term safety of these drugs emerged from reports in renal transplant and rheumatoid arthritis patients where an increased incidence of malignancies, particularly lymphomas and skin cancers was reported in the literature (Sheil et al., 1992; Gaya et al., 1995; Asten et al., 1999; Kinlen et al., 1985). Currently, this concern appears to be well established in patients with solid organ transplants on lifelong large doses of immunosuppressive therapy. This led to many researchers exploring the malignancy potential in patients with IBD treated with AZA and 6MP. To date 3 prospective cohort studies, 7 retrospective studies and 3 reviews (including 2 meta-analyses) have been published. Disappointingly, the results of these studies are divergent and the true impact of AZA and 6MP therapy on IBD malignancy risk remains controversial. In addition, the vast majority of the data on this question comes from Europe and North America, and no studies to date have focused on populations in subSaharan Africa.

\subsection{Aims and objectives}

In light of the potential risk of malignancy in these patients and the lack of consistent and convincing evidence regarding this question, we evaluated the association between azathioprine and/or 6-mercaptopurine use and the incidence of malignancy among IBD patients receiving care at a tertiary hospital in Cape Town. Our specific objectives therefore were three-fold:

a. To assess the incidence of malignancy particularly lymphoma and skin cancer in IBD patients on AZA or 6-MP, and to compare it with that of patients with IBD not on these agents.

b. To assess the factors that are independently associated with an increased risk of developing a malignancy.

c. To evaluate whether of the total malignancies that occur among IBD patients, skin cancers occur more frequently or not. 


\section{Literature Review}

\subsection{The history of AZA/6MP}

Azathioprine (AZA) was initially procured as a chemotherapy drug, although now it is rarely used for this indication. In addition to its use for immunosuppression in organ transplantation, autoimmune diseases such as rheumatoid arthritis, and a variety of dermatological conditions, this drug is also widely used for the treatment of Inflammatory Bowel Disease (Akash et al., 2006). It is a pro-drug, which is converted in the body to active metabolites one of which is 6-mercaptopurine. (refer to appendix section for a diagram of metabolites) Azathioprine acts to inhibit purine synthesis necessary for the proliferation of cells, especially, leukocytes and lymphocytes. The long-term side effects of this drug are unclear, however, perhaps the most concerning of these is the potential for inducing malignancies. AZA is listed as a human carcinogen in the 11th Report on Carcinogens of the U.S. Department of Health and Human Services. In another study azathioprine was shown to be carcinogenic and mutagenic at supra-therapeutic doses, and this was shown in animal and in vitro models (Cohen et al., 1983; Casey et al., 1968; Clark et al., 1975).

Laboratory data suggest that ultraviolet light and AZA may act synergistically to result in higher rates of skin cancer. Patients on higher doses (for example, patients with heart transplantation compared to those with kidney transplants who tend to be on lower immunosuppressive doses) and longer durations of AZA have been shown to have an increased risk of skin cancer, particularly, squamous cell carcinoma. This was shown in dermatology in patients on AZA for more than 4 years (Akash et al., 2006). In patients with renal transplant on immunosuppressive therapy, skin cancers are the commonest malignancies found to occur, and these cancers occur specifically in the light-exposed areas. This was shown experimentally by Dalton et al., 1990 and Kelly et al., 1989. Those patients on higher doses and longer durations of treatment have been shown to have higher incidences of skin cancers (Jensen et al., 1999; Westburg et al., 1973; Bottomley et al., 1995) particularly squamous cell carcinoma.

The risk of other cancers such as lymphoma is more difficult to estimate as a 
result of the conflicting results that have been obtained from numerous studies performed. However, it is thought that when lymphomas occur, they too, are associated with increasing duration of treatment with AZAVMP. These lymphomas are generally $\mathrm{B}-\mathrm{cell}$ in nature and are thought to be related to EBV infection and immunosuppression.

\subsection{Potential mechanisms for inducing skin cancer}

\subsubsection{The thiopurines}

The term "thiopurines" is used to describe the metabolites azathioprine, 6-mercaptopurine, and 6-thioguanine (6TG). The thiopurines are prodrugs which culminate in the formation of thioguanines which are the precursors of nucleic acid synthesis (Karran 2007). In general, thiopurines are chemically more reactive than the normal DNA bases which confer on them their therapeutic effects. The converse, however, is their potential for inducing malignancy when used longterm, due to this high reactivity (Karran 2007) which results in the susceptibility for unwanted reactions, for example, other chemical modification or methylation.

\subsubsection{Photosynthesisers}

It has been shown that these DNA bases are photodynamically active in free solution and undergo light-induced reactions that require molecular oxygen. Due to their ability to absorb UVA light, in solution both 6MP and 6TG are rapidy destroyed by UVA reactions that are dependent on oxygen. Therefore, in these reactions the thiopurines can act as Type 1 and Type 2 photosensitisers. In Type 1 sensitisers the free bases absorb UVA photons resulting in an excited triplet state 3 TP. This highly unstable compound can react with molecular oxygen leading to the formation of thiopurine radical species (TP's) and superoxide, which can be converted to highly reactive hydroxyl reactions $(\mathrm{OH})$ by Fenton-like reactions. In Type 2 reactions the thiopurines absorb UVA light and the energy produced results in the formation of molecular oxygen to generate singlet oxygen. Although both hydroxyl radicals and singlet oxygen are known to cause DNA damage, it is reactive oxygen which has been shown to cause the most damage in DNA in cells exposed to UV light (>90\% of which is UVA) (Karran 2007). 


\subsubsection{Incorporation of 6-TG to DNA}

6-Thioguanine (6-TG) is incorporated as a guanine analogue into DNA and this incorporation results in chromatid damage and DNA strand breaks. Furthermore, work done earlier by Lennard (1985) showed an increased level of intracellular 6-TG nucleotide (6-TGN) in renal transplant patients with skin lesions as compared to matched controls. They also showed that the thiol group on 6-TGN is oxidized at 320 to $360 \mathrm{~nm}$ (nanometers) UV light and suggested that there may be an interaction between UV and the incorporated 6-TG resulting in DNA damage to carcinogenic change.

\subsubsection{Increased levels of Sister Chromatid Exchanges (SCE's)}

Exposure to various carcinogenic chemicals and drugs has been shown to be associated with an elevated level of sister chromatid exchanges (SCE) in peripherallymphocytes. Increased SCE levels have been reported in azathioprinetreated patients both with renal and non-renal conditions. In this study, Dalton and colleagues studied SCE levels after exposure to UV light over the appropriate oxidizing wavelength in two groups of patients treated with azathioprine and in their control groups. The first group of patients was renal transplant recipients on azathioprine and prednisone, the second group were patients with skin conditions treated with azathioprine and these were compared to matched controls. The results showed a clear increase in SCE in both patient groups exposed to UV light with the greatest increase in the renal transplant recipients (RTR's), and an increase in patients not exposed to UV light in comparison to the controls. Both patient groups showed a disruption of the cell cycle following UV light exposure and this was measured using the proliferative rate index (PRI) but this was not so in controls. Therefore, this study showed evidence which supports the synergistic hypothesis between AZA and UV light and this correlates well with the clinical pattern of carcinogenesis observed in patients with renal transplants having a well-documented increased risk of neoplasia, particularly, skin cancers in the exposed areas (Dalton et al., 1990). 


\subsection{The efficacy of AZA/GMP in UC/CD}

As has been noted previously, azathioprine and 6-mercaptopurine are the most extensively used immunomodulators in $1 B D$ (Kwon et al., 2005). They have been shown (Present et al., 1980; Bouhnik et al., 1996) to be effective in the treatment of both active and steroid refractory Crohn's disease as well as in maintaining disease remission (Kwon et al., 2005). In UC, AZA and 6MP are effective in patients who are either steroid-dependant for control of their disease or steroid-refractory (Katz et al., 2007). Due to the slow onset of action of these drugs, their use is strategic, allowing for a discontinuation of steroids and maintaining a remission, rather than using these drugs for active disease (Katz et al., 2007). Thus the main use of these agents is for their steroid-sparing properties (IBD management guidelines 2004). It has been debated in the literature about the effectiveness of azathioprine in UC and "according to recent publications, azathioprine is almost equally effective in UC and CD" (Lakatos et al. 2007). Further evidence for the efficacy of AZA in UC comes from (Timmer et al., 2007) a Cochrane database systematic review, involving a Medline search of literature published from 1966 to 2006 and including randomised controlled trials of at least 12 months duration. It compared patients treated with AZA or 6MP to those receiving standard maintenance treatments with an aminosalicylate (mesalamine). Six studies that included 286 patients with UC were identified. As compared to placebo, AZA was found to be superior in maintaining a remission with an $O R=0.41(95 \% \mathrm{Cl} 0.23-0.70)$ in 4 of the trials. The remaining two trials that compared 6MP to mesalamine and AZA to sulfasalazine (the prototype drug for the aminosalicylates) showed contrasting results. Therefore, in this trial it was concluded that AZA may be effective maintenance therapy for patients with UC.

In CD it is approximated that $50 \%$ of patients become steroid-dependant or resistant particularly those patients that continue to smoke and in those with more severe disease involving the colon (Katz et al., 2007). Both AZA and 6MP are effective treatments in this group and can maintain remission in 40-60\% of patients. Azathioprine, in particular, is effective in maintaining remission for at least 4 years (Fraser et al., 2002) however, data suggests that about $10 \%$ of patients will have a relapse per year if the therapy is discontinued although the majority will regain a response if the treatment is re-introduced (Katz et al., 2007). 
In clinical practice, AZA and 6-MP are used virtually interchangeably with the exception of dosing. AZA is generally used in doses of 2 to $2.5 \mathrm{mg} / \mathrm{kg} /$ day, whereas $6-\mathrm{MP}$ is given in doses of 1 to $1.5 \mathrm{mg} / \mathrm{kg} /$ day (Sleisenger and Fordtran's textbook $8^{\text {th }}$ edition).

\subsubsection{Mechanism of action of AZA/6MP}

The mechanism of action of these two agents is incompletely understood, however several mechanisms have been proposed. The metabolites of both agents inhibit de novo synthesis of purine ribonucleotides (which are the building blocks of DNA), thereby inhibiting cell proliferation. Furthermore both drugs inhibit cell-mediated immunity and cause a reduction in the number of circulating natural killer cells, thus resulting in a dampened immunological response. More recently azathioprine and 6-MP have been shown via complex mechanisms (Tiede et al., 2003) to effect apoptosis (cell death) and thus result in a diminished immune response. Azathioprine and its metabolites may have immunosuppressive properties beyond those of the metabolites produced in common with 6-MP.

\subsection{Data from renal transplantRheumatoid arthritis patients}

\subsubsection{Malignancy risk}

\subsubsection{Renal transplantation}

The potential causal association between the use of AZA/6MP and malignancy was first noticed and reported in patients who underwent renal transplantation and were immunosuppressed with these agents. It was reported (Sheil et al., 1992 and Gaya et al., 1995) that there was an increase in the numbers of skin cancers and B-cell non-Hodgkin's lymphoma (NHL) in renal transplant patients. In another follow-up study conducted by the same authors renal transplant recipients had an increased risk of cancers particularly skin cancers, NHL and other solid organ tumours (Sheil et al., 1997). In another study (Kishikawa et al., 1998) it was shown that the duration of treatment with these agents seems to be a factor in the incidence of tumours. This is most notable after 10 years of treatment: $3.9 \%$ and $13.9 \%$ of renal transplant patients were found to develop any cancer after 10 
years and 20 years, respectively, of AZA/6MP or cyclosporine use.

\subsubsection{Rheumatoid arthritis}

Similarly, in patients with rheumatoid arthritis, there have been several large follow-up studies which have found an increased risk of malignancy, particularly lymphoma, in patients exposed to AZA or 6MP. The first study (a cohort study) showed a small increase in deaths in patients exposed to thiopurines, most of which were due to malignancy. In this study the risk of developing lymphoma was increased 7 -fold in the immunosuppressed group (Jones et al., 1996). In another large study of 1773 patients with heumatoid arthritis from 15 European countries treated with the thiopurines, followed up for 12266 person years, the relative risk was $3.74(95 \% \mathrm{Cl}, 1.5-9.5)$ for developing a cancer involving the immune system, bladder or skin. When restricting the analysis to the use of only azathioprine, the results were similar and patients treated for more than 10 years were more likely to develop malignancy than those treated for less than one year (Asten et al., 1999). Yet another study conducted on patients with rheumatoid arthritis conducted by Kinlen (1985) showed similar results. In this study not only was the risk of lymphoma increased in those treated with AZA or cyclophosphamide (13-fold), but it was found to be high in rheumatoid arthritis patients who were not treated with these agents. This suggests, therefore, an added effect of immunosuppression on the risk of cancer in these patients.

The evidence for patients with rheumatoid arthritis and skin cancers is more divergent with some studies showing no increased incidence of malignancies (Connell et al., 1994; Fraser et al., 2002) and yet others showing a greater risk (Asten et al., 1999; Silman et al., 1988).

\subsubsection{Other conditions}

Correspondingly, the association between use of immunosuppressives and an increased incidence of malignancy has been shown in other conditions: multiple sclerosis (Confavreux et al., 1996), psoriasis and dermatomyositis (Phillips et al., 1987) and in recipients of heart transplants where Lloveras (1995) showed that in those patients on lower doses of immunosuppression, the incidence of 
lymphomas was reduced.

\subsection{Data in the general IBD population}

\subsubsection{Lymphoma}

In order to assess as accurately as possible the role of immunosuppressive therapy in increasing the risk of lymphoma it is important to review the occurrence of lymphoma in IBD patients not treated with immunosuppressive agents. This allows for a determination of the underlying baseline risk in IBD patients.

Lymphoma occurring in patients with IBD was first described by Bargen in 1928 (Kwon et al., 2005). The majority of these lymphomas are said to occur in areas of active inflammation suggesting that chronic active inflammation increases the potential for malignant change in the bowel.

The review of the literature by Kwon (2005) identified 14 IBD patient cohorts that examined the association between lymphoma in IBD. The majority of the studies did not show an association between lymphoma and IBD. The largest of these with the most impressive results was that using the GPRD (General Practice Research Database) in the UK that screened a database of 8 million patients, identifying close to 17000 IBD patients. These were compared to age, sex and general practitioner controls. Eighteen cases of lymphoma were found with a relative risk of $1.20(95 \% \mathrm{Cl}, 0.67-20.6)$. The results were no different when analysed according to having UC or $\mathrm{CD}$ and when comparing those on immunosuppression to those not on immunosuppression. In his review article, Kwon describes 8 population and hospital-based studies that were done on patients with IBD, all of which did not identify an increased risk of lymphoma. However, he also evaluates and reports on 7 other studies that did show a statistically increased risk of lymphoma in IBD cohorts. Therefore, looking at all the available data, the issue of whether lymphoma is higher among patients with IBD remains inconclusive as the hospital and population-based cohort studies are contradictory. Overall though, the risk of lymphoma in IBD patients appears to be significantly lower than that associated with immunosuppressed transplant recipients. 


\subsubsection{Small bowel cancer in $C D$}

The first case of small bowel (jejunal) cancer complicating CD was reported as early as 1956. Since then reports have been consistent that the risk appears to be increased when compared to that in the general population. However, the magnitude of this increased risk as well as the factors associated with this risk was not clear. Several studies have estimated this risk to be six times that in the general population (Bernstein et al., 2006). In a recent meta-analysis of populationmbased cohort studies by Jess et al., 2005, the risk of intestinal malignancy in patients with CD was evaluated. Six papers were included and showed a pooled SIR for $\mathrm{CRC}$ of $1.9(95 \% \mathrm{Cl}, 1.4-2.5$. With respect to small bowel malignancy five studies reported SIR's in the range $3.4-66.7$, with an overall pooled estimate of $27.1(95 \% \mathrm{Cl}, 14.9-49.2)$. Thus, this study clearly showed an increase in the risk of small bowel cancer in patients with CD compared to the general population.

The characteristics of small bowel adenocarcinoma complicating Crohn's disease differ from those that occur spontaneously. Crohn's associated small bowel adenocarcinomas tend to occur at a younger mean age, are male predominant, occur more commonly in the distal small bowel and have a poorer outcome. Factors that have been postulated to increase the risk for the development of small bowel adenocarcinoma in Crohn's disease include: male sex, duration of disease, associated fistulous disease, and surgically excluded loops of bowel (Bernstein et al., 2006).

\subsubsection{Small bowel cancer in UC}

The literature on the occurrence of small bowel adenocarcinoma in UC is scanty however this risk is generally thought to be low. There are however numerous reports on adenocarcinoma occurring after surgical procedures. Restorative proctocolectomy (RPC) has been accepted as optimal surgical therapy for most patients with ulcerative colitis. The occurrence of adenocarcinoma adjacent to the ileoanal anastomotic site for ulcerative colitis is a serious but rare outcome. To date are 19 reported cases however, overall, the risk of this complication is 
rare (Lee et al., 2005). Similarly, adenocarcinoma arising at the ileostomy site has been reported in the literature in seven cases (Roberts et al., 1989).

\subsection{3. $C R C$ and $I B D$}

\subsubsection{1. $C R C$ in $C D$}

It was Warren and Somers who first described a case of colonic cancer in a patient with CD colitis (Bernstein et al., 2006). Since then both the incidence and the cancer risk in CD have been debated. A study done by Gyde et al (1980) found a fourfold risk of colorectal carcinoma in 513 patients in the West Midlands section of England. In another study by Ekbom et al (1991) which included 1655 Swedish patients with Crohn's disease, an increased risk of colon cancer was found only in those patients with colitis. Gillen et al (1994) found an increased risk of colorectal cancer in patients who developed Crohn's disease before 30 years of age. In contrast 3 other population-based studies have shown no increased risk of cancer in this cohort of patients. Munkholm et al (1993) evaluated a cohort of 373 Danish patients and found no increase in the incidence of colorectal carcinoma. The flaw of this study was that a third of these patients $(29 \%)$ had undergone prior partial or total colonic resection secondary to severe colitis. This aggressive surgical approach to treatment most likely reduced the overall incidence of colon carcinoma. Two other large population studies from Israel and Minnesota also showed no increased risk of colorectal carcinoma in Crohn's disease.

The factors that have been postulated to increase the risk of colonic cancer in Crohn's disease include the age of onset, the presence of strictures and/or fistulae, and right-sided colonic disease (Bernstein et al., 2006). The risk for the development of colorectal carcinoma in Crohn's disease patients is greater than that in the general population, but this risk is not as well defined as the risk of colorectal carcinoma in patients with ulcerative colitis. Additional risk factors for the development of colorectal carcinoma in Crohn's disease include the presence of stricture and/or fistulous disease in the colon. Gillen et al (1994) in a cohort of patients with ulcerative and Crohn's colitis, found an 18-fold increased risk for developing colorectal carcinoma in Crohn's colitis. The cumulative frequency of risk for developing colorectal carcinoma in extensive Crohn's colitis was $8 \%$ at 
22 years from onset of symptoms. This compares with the risk seen in UC, thus, it can be assumed that the risk of the development of colorectal carcinoma in Crohn's colitis with longstanding extensive disease is similar to the risk for the development of colorectal carcinoma in ulcerative colitis. This is an important consideration because currently there is no consensus regarding the screening for cancer in patients with $C D$ colitis.

The development of carcinoma within Crohn's anorectal fistulae and rectovaginal fistulae is well described. Connell et al as referenced by Bernstein et al (2006), reported the development of five anorectal squamous cell carcinomas in patients with longstanding anorectal fistulous disease. Therefore it is recommended that any fistula that does not respond to conventional therapy or that occurs distal to a stricture site must arouse the suspicion of an underlying malignancy and be brushed and biopsied accordingly.

\subsubsection{2. $C R C$ in $U C$}

The incidence of the development of colorectal carcinoma in ulcerative colitis is $0.5-1 \%$ peryear after the first decade of extensive colitis. Patients with longstanding extensive colitis appear to be at the highest risk of developing colorectal carcinoma in both ulcerative colitis and Crohn's disease (Bernstein et al., 2006). Winther (2004) followed-up a population-based cohort of 1160 patients with UC diagnosed in Copenhagen County for up to 36 years $(22,290$ person-years) to analyze the overall and site-specific cancer risk A total of 124 malignancies were observed compared with 139.85 expected, SMR $=0.89(95 \% \mathrm{Cl}, 0.74-1.07)$. The observed number of CRCs was almost exactly equal to expected: 13 cases vs. 12.42, SMR $=1.05(95 \% \mathrm{Cl}, 0.56-1.79)$. The conclusion was, therefore, that neither the overall cancer risk, nor the $\mathrm{CRC}$ risk, was increased in this population-based cohort after a median of 19 years of follow-up. This remarkable result could be explained by the fact that their management of patients included an active surgical approach in the medical treatment failures and the long-term use of 5-aminosalicylic acid (5-ASA) to prevent relapses.

In another study conducted in Scandanavia, Stockholm (Karlen et al., 1999), a total of 121 versus 97 expected, SMR $=1.4(\mathrm{Cl}, 1.1-1.6)$. Overall there were an excess number of colorectal cancers and hepatobiliary cancers in men and this was associated with primary sclerosing cholangitis. Therefore, in UC patients, 
the common sites of carcinoids are the appendix, ileum and rectum. It remains unclear whether these occur co-incidentally or whether patients with UC are at a higher risk than those without IBD.

\subsubsection{Skin cancer}

An increased risk for the development of squamous cell carcinoma of the skin and malignant melanoma has been described in $\mathrm{CD}$. Ekbom et al (1991) followed 1655 patients with Crohn's disease and found a $5.5 \%$ increased relative risk for the development of squamous cell skin cancer in these patients when compared with the general population. In another study, Greenstein et al (1985) noted the development of nine malignant melanomas in 1657 patients with Crohn's disease followed from 1960 to 1983 . This is 50 times the expected risk for the development of malignant melanoma in the general population.

\subsubsection{Miscellaneous}

\subsubsection{Renal}

No studies have found an increased risk for the development of bladder and urinary tract tumors in Crohn's disease. Renal cell carcinoma has been reported in a single case of Crohn's colitis. Bladder involvement in Crohn's disease is not uncommon with the development of fistulae between the inflamed bowel and bladder. Despite this complication, only five cases of transitional carcinoma of the bladder have been reported; the most recent case was in a 15 year old with Crohn's ileocolitis with an enteric fistula but without any fistulae to the bladder (Bernstein et al., 1996)

\section{6. Data in IBD patients on immunosuppression}

\subsubsection{Lymphoma}

Numerous studies in IBD patients evaluating the risk of cancer have been done between 1985 to the present. The majority of these reports, comprising 
both retrospective and prospective studies, have evaluated the risk of developing lymphoma with conflicting results. In an attempt to resolve the concern of whether the use of immunosuppressive agents used in IBD patients pose the same malignancy risk as that observed in solid organ transplant recipients, studies have been conducted examining the incidence of lymphoma in IBD patients receiving azathioprine, 6-mercaptopurine, cyclosporine and methotrexate. Overall, nine studies have been published with the majority of patients receiving either AZA or 6MP. In addition one review article (2005) and two meta-analyses have been conducted recently, the latter in 2005 and 2007 respectively, which included 6 and 9 cohort studies respectively.

Of the nine original articles published, 6 were retrospective and the remaining 3 prospective cohort studies. The earliest study was conducted by Kinlen et al (1985) and showed an increased incidence of skin cancer and NHL (1 case) in patients who were not transplant recipients. Subsequently a study conducted on 396 IBD patients (Present et al., 1989) reported one case of histiocytic lymphoma of the brain in a patient with UC which was considered to be probably associated with the use of $6 \mathrm{MP}$. In another study by Connell et al published in 1994, 732 patients with both UC and CD were examined. These patients were followed up for a median period of 9 years from initiation of treatment with azathioprine. A higher than expected number of CRC was observed, but no cases of lymphoma were found in this study. In a study by Korelitz et al (1999) which retrospectively assessed the records of $550 \mathrm{IBD}$ patients treated with 6-MP, of the 25 patients who developed a malignancy, 2 had a lymphoma one of which was a CNS lymphoma. In yet another study, 626 patients were treated with AZA and no association with all cancer was found despite the fact that in this group 3 lymphomas were detected (Fraser et al., 2002). Thirty-one cancers were observed in 30 patients treated with azathioprine $(4.5 \%)$ and 77 cancers were observed in 70 patients not treated with azathioprine $(4.5 \%)$.

In 2001 Lewis et al performed a retrospective cohort study using information from the General Practice Research Database in the United Kingdom. This was a large study which included 6605 patients with CD, 10391 with UC, and 60506 age and sex-matched controls. Remarkably in this large cohort only 1 lymphoma was found in a patient with UC. Although the relative risk of lymphoma in those treated compared to those not treated was $1.27(95 \% \mathrm{Cl}, 0.03-8.20)$, this was 
not significant as the RR overlapped the null. The most recent of the published original articles was by Glazier et al in 2005 that reported on 285 patients all of whom were treated with $6 \mathrm{MP}$. Although the risk of malignancy was not specifically studied, 3 lymphomas were detected.

In contrast and strikingly, a retrospective study of 782 IBD patients (238 on AZA, 6MP, CSA or MTX) conducted in an Irish hospital showed a 59-fold increase in the risk of NHL in those that received immunosuppression compared to their treatment-naive counterparts. In this study (Farrell et al., 2000) 4 patients had NHL. The concern in this study regarding the findings is that this study was conducted in a single centre, and 1 patient was on MTX combined with CSA. Thus, the combined effect of 2 immunosuppressives could have resulted in an inflated estimate of the risk.

The two meta-analyses performed also yielded contrasting results; the first meta-analysis showed a four-fold increased risk of lymphoma in patients treated with AZA or 6MP (Kandiel et al., 2004). In total there were 11 lymphomas found. In the most recent meta-analyses by Masunga et al (2007) there was no association between the use of immunosuppressive therapy (azathioprine, 6-mercaptopurine, cyclosporine Aor methotrexate) and the development of lymphoma. The difference in these two meta-analyses could be accounted for by the lack of comparability: in the first meta-analysis, only AZA and 6MP were used, and the outcome of interest was lymphoma, whereas in the second meta-analysis, the outcome of interest was all cancer, and all the immunosuppressives used for the treatment of IBD were included in the study. Thus, due to the broadness of the research question in the latter study, the risk of malignancy could have been diluted.

\subsubsection{Skin cancer}

While laboratory evidence speaks to a possible synergistic interaction between ultraviolet light exposure and azathioprine, there is only a single case report of a skin cancer occurring in a patient with IBD treated with immunomodulating drugs. Although not robust evidence, Austin et al (2001) reports on a case of a 42 year old Caucasian female with CD who was using azathioprine for 8 years and also regularly tanned in a sunbed. She developed an intra-epidermal carcinoma of 
the skin. To our knowledge this is the only case of skin cancer reported in a patient with IBD.

\subsubsection{Other cancers}

\subsubsection{Hepatoma}

The reports of othertypes of malignancies in IBD patients on immunosuppressive agents come mainly from case reports. In a study conducted in Tokyo, Nakao et al (2005) report on a 64 year old man who was treated with prednisolone and 6-mercaptopurine for an eight year period for UC and in whom hepatocellular carcinoma ( $\mathrm{HCC}$ ) was detected incidentally. This patient was hepatitis $\mathrm{C}$ virus negative (commonly associated with $\mathrm{HCC}$ ). A technique of comparative genomic hybridization was employed to detect chromosomal abnormalities and gains in chromosomes $1 q, 3 p$ and $8 p$ were found which are suggestive that the HCC was related to the use of immunosuppressive therapy and not a viral agent.

\subsubsection{Tongue}

Also reported (Li et al., 2003) is a case of cancer of the tongue in a 34 year old non-smoking patient with CD treated with AZA. Histology of the tongue showed a squamous cell carcinoma. This type of cancer has not been previously described in association with $\mathrm{CD}$.

\subsubsection{Vulva}

Greenstein et al reported the development of two cancers of the vulva in a cohort of 1227 Crohn's patients followed at Mt. Sinai Hospital, New York, over a $22-y r$ period. Both patients were 56 yr old and had Crohn's colitis. One patient had perianal disease. These two cases of cancer of the vulva are far in excess of the expected incidence of this disorder at this age (Bernstein et al., 1996). 
A single case of Kaposi's sarcoma of the colon has been reported in a 36-yrold, HIV-negative woman with Crohn's disease being treated with azathioprine for 11 months before the diagnosis of the Kaposi's sarcoma. The Kaposi's lesions were noted to regress with the discontinuation of azathioprine.

\subsubsection{Others}

The development of a leiomyosarcoma in an area of active ileal inflammation in Crohn's disease has been reported (Bernstein et al., 1996).

\subsection{Summary}

Despite the fact that the issue of the potential for AZA and 6MP to induce malignancies has been known since the 1930's and in IBD patients formally studied since 1985, the scientific data to date including two meta-analyses (thought to be the most superior of the study designs), lacks consistency and the question still remains: Can the use of immunosuppressive therapy be causally related to the development of malignancies? 


\section{Materials and methods}

\subsection{Study design}

A concurrent retrospective cohort study was conducted based on an existing database of IBD patients attending the GIT clinic at GSH. The database was used to identify all IBD patients attending the clinic, their demographics, and data pertaining to both the use of AZA or 6MP and the malignancies that were identified. The patients were retrospectively "followed-up" from the time of diagnosis of $\mathrm{BBD}$, the point of commencement of $A Z A$ or $6 \mathrm{MP}$, and the time to developing a malignancy. In cases where the data was missing, incomplete or incongruous, the patient records were recalled and manually searched. This was particularly true for the use of AZA or 6MP. For the majority of the patients on the database, information about whether or not and the type of immunomodulating agent used was available. However, for the total duration and dosing of therapy the database was grossly deficient. This necessitated a manual search for this information for the patients that were recorded on the database as ever having been administered AZA or 6MP. Two hundred and forty six patients on the database were treated with AZAVGMP but only 123 of these records could be accessed. Due to time constraints no other efforts to retrieve missing information were undertaken.

This retrospective study design was employed because the resources (both human and financial) to conduct a prospective follow-up study are inaccessible and this design could potentially answer the research question as efficiently as a prospective cohort study. Being able to answer this question would be invaluable in informing the management of these patients.

\subsection{The database}

Initially the folders of all patients that had been attending the IBD clinic from the 1960 's to the commencement of the database were retrieved and reviewed and all the relevant data pertaining to their disease was extracted and entered into the database. During the follow-up period if there were any new developments, for instance, the commencement of an immunomodulating agent, this data was loaded into the database, so as to keep an updated record at all times. 
Subsequently, as new patients were referred to the clinic, if a diagnosis of IBD was made, these patients were also sequentially entered into the database. Therefore, for each patient the start of the period of observation is taken as day of entry into the database. Over the last few years, the database has evolved and contains numerous and varied variables on each patient with IBD who has attended or is currently still attending the clinic. This database has yielded a number of retrospective analyses of issues relating to the descriptive and/or analytical aspects of IBD.

\subsection{Study setting/population}

This database was utilised to conduct a retrospective study of all patients diagnosed with IBD since the 1960's to a cut-off date of June 2007, who attended the IBD clinic at the Gastro-Intestinal (GIT) unit at Groote Schuur Hospital in Cape Town. This hospital is a tertiary referral centre and services a large population of patients of all races within and around the Western Cape. Some patients that reside in neighbouring countries are also occasionally seen to at this clinic. Currently the clinic is staffed by two full-time consultant Gastro-enterologists, three specialist registrars, and a single Senior House Officer. In each week, four dedicated IBD clinics (Monday to Thursday) are run; in addition patients with IBD are seen ad hoc without an appointment whenever they feel ill. Thus, patients attending at this clinic receive highly specialised tertiary level management. When medical therapy fails these patients are referred to a parallel unit for colorectal surgery. The patients seen here are patients over the age of 12 years; those younger than 12 are seen at the nearby Red Cross Children's Hospital.

\subsection{Inclusion criteria}

The inclusion criteria for this analysis were:

a) A confirmed diagnosis of IBD.

b) On-going follow-up and attendance at the GIT clinic within the last 6 months.

c) Age $>12$ years 


\subsection{Exclusion criteria}

The exclusion criteria for this analysis were:

a) A patient that has not been seen at the clinic within the preceding 24 months.

b) A diagnosis of malignancy that precedes the start of the period of observation.

c) All malignancies that occurred within 18 months of thiopurine initiation as causality is questionable. Malignancies attributable to IBD (CRC, cholangioca and small bowel adenocarcinoma) were included, but analysed separately in some instances.

\subsection{Definition of terms/Measurements}

\subsubsection{Period of IBD follow-up}

The period of IBD follow-up was defined as the time between the diagnosis of IBD and the end of the study, loss to follow-up or death.

\subsubsection{Disease and extent}

Inflammatory Bowel Disease was defined as a chronic inflammation of the affected part of the gut as per the usual combined criteria of clinical, radiological, and histological evidence. In addition to UC and CD, there are two additional conditions which fall within the spectrum of $\mathrm{BD}$. A diagnosis of indeterminate colitis (IC) is based on endoscopic, histologic, and radiologic findings when the criteria for either Crohn's colitis or ulcerative colitis (UC) cannot be definitively established (Burakoff 2004). At the time of initial diagnosis of inflammatory bowel disease, up to $10 \%$ to $15 \%$ of patients will be diagnosed as having $\mathrm{IC}$. Over time, greater than $50 \%$ of patients with $1 \mathrm{C}$ will be given a diagnosis of UC or Crohn's, with the majority being diagnosed with UC (Burakoff et al., 2004). 
The extent of the disease is also defined. An internationally-accepted classification of extent of disease is as follows: for UC (which affects the colon) inflammation extending from the rectum up to and including the splenic flexure is termed left-sided colitis. When the inflammation extends beyond the splenic flexure it is termed extensive colitis. If the entire colon is involved it is termed pancolitis. With respect to $C D$ the disease may affect the small bowel (ileitis), the large bowel (colitis) or both (ileo-colitis). Accordingly the extent of the disease was defined as the maximum recorded macroscopic disease seen at colonoscopy.

\subsubsection{Malignancy}

Any cancer affecting any part of the body that was noted was included in the study. Those patients that had a malignancy at the start of the observation period were excluded from the study. Patients found to have high-grade dysplasia of the colon were classified as having colorectal cancer (CRC) due to the evidence that exist that this lesion will likely progress to CRC. Similarly, patients with high grade Cervical Intra-epithelial Neoplasia (CIN) of the cervix were classified as having cancer of the cervix.

\subsubsection{Immunomodulator therapy}

Patients started on immunomodulating therapy are usually commenced on AZA. If there is intolerance to the agent it is common practice to substitute AZA for 6MP. Similarly for reasons of sepsis, non-compliance or other factors (such as breast feeding, pregnancy) patients may be on therapy intermittently. Although it is safe to use AZA/6MP in pregnancy, the majority of patients opt to stop therapy during their pregnancies. Thus, the assignment of AZA or GMP therapy when the patient has been on both was taken as the drug that the patient was on the longest. Doses, however, were calculated for each drug separately and added to the total dosing amount for the cohort. The total duration of therapy was assessed and calculated manually, adding up all the periods of individual therapy and approximating it to a monthly period. Thus, the total duration of therapy in months was calculated for each patient. The data for the use of AZA or 6MP was grouped into the "treatment" group, whilst those not treated with these 
agents represented the "no treatment" group. Some patients were captured on the database as having been on either AZA or 6MP; however on reviewing the clinical and pharmacy notes, there was no record of use of these agents. In this case, these patients were grouped as the "unknown treatment status" group.

The period of follow-up from AZA or 6MP initiation to data analysis is one of the variables included and represents the mean period of follow-up with the use of these agents.

\subsection{Analysis}

The data from the database was in the form of a spreadsheet in Microsoft Access. The missing data that was subsequently collected was also entered into Microsoft Access. The data was then exported into Stata version 9 (Stata Corporation, College Station, Texas) data editor. Here the data was edited and formatted to make it suitable for analysis using Stata (e.g. the categorical variables were coded).

The variables included in this study were:

a) Age in years

b) Age at diagnosis of IBD in years

c) Gender (male or female)

d) Smoking history (current, ex-smoker, non-smoker and missing data)

e) Ethnic background (White, Coloured, Black and Asian)

f) Type of IBD (UC or CD)

g) Disease extent

h) Immunosuppression (AZAV6MP or no treatment or unknown treatment status)

i) Malignancy (primary outcome)

The first step in analysing the data was a descriptive survey of all the variables. 
Exploratory data analysis was performed and results are reported as medians and inter-quartile ranges (IQR) as most of the variables were non-normally distributed. The categorical variables were summarised using frequency tables and were expressed as percentages.

Bivariate analysis using box plots of continuous variables for the different groups as defined by the categorical variables are shown. The chi-square test or Student's t-test was employed to investigate the differences in the demographics, diagnostic and other patient characteristics and the incidence of malignancy between those treated and those not treated with AZA or 6MP. Kaplan Meier survival curves were generated and to compare survival rates between the two groups the log-rank test was used.

Multivariate analysis using Cox's proportional hazards logistic regression was undertaken to evaluate the factors that independently were associated with the outcome. Different models based on different combinations of the covariates were fitted and compared using the Bayesian Information Criterion (BIC) score to select the most clinically relevant and parsimonious model. The best model was validated using the residuals; Cox-Snell residuals to assess overall model fit, Martingale residuals to assess the correct functional form of the covariates, Schoenfeld residuals to ensure that the proportional hazards assumption was upheld and deviance residuals to examine the accuracy of the model and to identify outlying values that could significantly influence the validity of the model.

Finally, a subgroup analysis of the cases of lymphoma, CRC and skin cancer was done to evaluate the differences in the rates of these malignancies in the two groups. In situations where the numbers were small a Fisher's exact test was utilised to compare proportions. All statistical tests are 2-sided at a type 1 error rate of 0.05 .

\subsection{Ethics}

Due to the nature of this retrospective review, it was not requisite to obtain individual consent from each of the participants. However, a protocol was formulated and submitted to the University of Cape Town Human Research Ethics 
Committee who granted permission for the conduct of this study. This study was conducted in accordance with ethical practice as embodied in the World Medical Association Declaration of Helsinki that took place in Edinburgh in 2000.

All the information retrieved in this study was treated as privileged and with strictest confidence. In the event of the identification of a malignancy by the investigator, the patient was promptly referred to the relevant speciality for treatment.

The results of this study are intended to be used for the sole purpose of advancing the medical knowledge and care of patients either through the day-today management of the patients or to inform treatment guidelines. The findings of this study whether positive or negative will be disseminated through publication and presentation at clinical meetings. Consequently, despite the fact that some patients in this cohort may not benefit from the information generated by this study, many more IBD patients both on and off immunomodulating therapy stand to gain significantly irrespective of the outcome of the study. If the results are negative, that is no association shown, those that are on therapy can continue with therapy until remission without a fear of developing a malignant lesion. In contrast, if the results suggest a 'causal' association, those patients on AZA or 6MP will still benefit in that they can now be more vigorously screened and followed-up for malignancy. In those that have achieved a remission, treatment can be stopped.

This study did not require funding, and the author has no specific financial or professional interest for or against the use of immune suppressant therapy in IBD patients; as such, there is no conflict of interest to be declared. 


\section{Results}

\subsection{Descriptive statistics}

There were 1282 patient records in the database, 198 of which had one or more missing exposure (AZA/6MP use and IBD diagnosis) or outcome (malignancy) variables. These were excluded and thus in total 1084 records (containing the majority of the important information) were analysed (Fig. 1).

\subsubsection{Patient demographic characteristics}

The median age of the cohort at diagnosis of IBD was 34 years (IQR 24-46). The majority of the cohort was female comprising $61 \%$. The majority of patients were smokers (39\%) at the time of diagnosis, while $32 \%$ were non-smokers and $14 \%$ were ex-smokers. In $15 \%$, no data is available. The majority of patients were of mixed ancestry, so-called Coloureds (70\%), followed by Caucasians $(22 \%)$, Africans $(5 \%)$, Asians (1.6\%) and finally $1.6 \%$ in whom the ethnicity was not recorded.

\subsubsection{IBD type and disease extent}

The majority of patients had UC 50\% (538 patients), whilst $47 \%$ (514 patients) had $\mathrm{CD}$. The remainder, a small percent $3 \%$ (32 patients) were diagnosed with IC. In CD the majority of patients had extensive disease with $18 \%(200$ patients) with CD ileo-colitis, followed by ileitis in $17 \%$ (183 patients), and $10 \%$ (113 patients) with colitis. In UC the proportions of extensive disease compared to limited disease were similar at $20 \%$ each, whilst proctitis was seen in $5 \%(58$ patients). In another 5\% (59 patients) of the cohort no data were available.

\subsubsection{Duration of follow-up}

The mean duration of IBD follow up was 9.9 years (IQR $3.3-18.4$ ) with a total person time of 14350 person years. Forty nine cases of cancer were observed, 


\begin{tabular}{|c|c|c|c|c|c|c|c|}
\hline Variable & $\begin{array}{l}\text { Total colhor } \\
(n=1084)\end{array}$ & $\begin{array}{l}\text { No treatment } \\
\text { group }(\mathrm{n}=336)\end{array}$ & $\begin{array}{l}\text { Treated group } \\
(1=123)\end{array}$ & $\begin{array}{l}\text { P. value (treated } \\
\text { vs nol) }\end{array}$ & $\begin{array}{l}\text { Unkinown } \\
\text { treatment } \\
\text { status (n=125) }\end{array}$ & $\begin{array}{l}\text { Pvalie } \\
\text { (umknowi vs } \\
\text { not) }\end{array}$ & $\begin{array}{l}\text { P.value } \\
\text { (minnown vs } \\
\text { treated) }\end{array}$ \\
\hline $\begin{array}{l}\text { Age (years) } \\
\text { Median (IQR) }\end{array}$ & $33(1 \mathrm{QR} 25-46)$ & $34(10 R 25-47)$ & 29 (IOR 22-39) & 0.0001 & 33 (IOR 24-45) & 0.4520 & 0.0173 \\
\hline $\begin{array}{l}\text { Age at diagnosis } \\
\text { (years) } \\
\text { Median (IOR) }\end{array}$ & 34 (IOR 24-46) & 34 (IOP 25-47) & 29 (IOR 22-39) & 0.0001 & $33(\operatorname{IOR} 23-45)$ & 0.2871 & 0.0334 \\
\hline $\begin{array}{l}\text { Smoking \% (n) } \\
\text { Current } \\
\text { Non-smoker } \\
\text { Ex-smoker } \\
\text { Missing }\end{array}$ & $\begin{array}{l}* 961 \\
39 \%(372) \\
32 \%(304) \\
14 \%(131) \\
16 \%(154)\end{array}$ & $\begin{array}{l}37 \%(270) \\
34 \%(253) \\
15 \%(113) \\
13 \%(99)\end{array}$ & $\begin{array}{l}62 \%(72) \\
18 \%(21) \\
15 \%(17) \\
6 \%(7)\end{array}$ & 0.000 & $\begin{array}{l}28 \%(30) \\
28 \%(30) \\
1 \%(1) \\
44 \%(48)\end{array}$ & 0.000 & 0.000 \\
\hline $\begin{array}{l}\text { Ethnicity \% (n) } \\
\text { Mixed race } \\
\text { White } \\
\text { Black } \\
\text { Asian } \\
\text { Missing }\end{array}$ & $\begin{array}{l}1080 \\
70 \%(757) \\
22 \%(240) \\
5 \%(49) \\
1.6 \%(17) \\
1.6 \%(17)\end{array}$ & $\begin{array}{l}72 \%(599) \\
21 \%(177) \\
5 \%(38) \\
1.7 \%(14) \\
0.8 \%(7)\end{array}$ & $\begin{array}{l}80 \%(99) \\
14 \%(17) \\
3.2 \%(4) \\
1.6 \%(2) \\
0.8 \%(1)\end{array}$ & 0.352 & $\begin{array}{l}48 \%(59) \\
38 \%(46) \\
6 \%(7) \\
0.8 \%(1) \\
7.8 \%(9)\end{array}$ & 0.000 & 0.000 \\
\hline $\begin{array}{l}\text { IBD ype } \%(n) \\
\mathrm{CD} \\
\text { UC } \\
1 \mathrm{C}\end{array}$ & $\begin{array}{l}47 \%(514) \\
50 \%(538) \\
3 \%(32)\end{array}$ & $\begin{array}{l}42 \%(355) \\
54 \%(454) \\
3 \%(27)\end{array}$ & $\begin{array}{l}83 \%(102) \\
15 \%(18) \\
2.4 \%(3)\end{array}$ & 0.000 & $\begin{array}{l}46 \%(57) \\
53 \%(66) \\
1.6 \%(2)\end{array}$ & 0.535 & 0.000 \\
\hline $\begin{array}{l}\text { Disease-extent \% (n) } \\
\text { CD lleo-colitis } \\
\text { CD ileitis } \\
\text { CD colitis } \\
\text { UC extensive } \\
\text { UC limited } \\
\text { UC proctitis } \\
\text { IC exlensive } \\
\text { IC limited }\end{array}$ & $\begin{array}{l}1082 \\
18 \%(200) \\
17 \%(183) \\
10 \%(113) \\
20 \%(220) \\
20 \%(221) \\
5.3 \%(58) \\
1.5 \%(16) \\
1.0 \%(12)\end{array}$ & $\begin{array}{l}15 \%(127) \\
16 \%(133) \\
10 \%(86) \\
22 \%(187) \\
25 \%(207) \\
6 \%(46) \\
1.6 \%(13) \\
1.3 \%(11)\end{array}$ & $\begin{array}{l}45 \%(55) \\
23 \%(28) \\
15 \%(19) \\
11 \%(13) \\
2.4 \%(3) \\
0.8 \%(1) \\
2.4 \%(3) \\
0 \%(0)\end{array}$ & 0.000 & $\begin{array}{l}15 \%(18) \\
18 \%(22) \\
6.4 \%(8) \\
16 \%(20) \\
9 \%(11) \\
9 \%(11) \\
0 \%(0) \\
0.8 \%(1)\end{array}$ & 0.000 & 0.000 \\
\hline
\end{tabular}




\subsubsection{Malignancy}

A total of 49 cancers, representing $4.5 \%$ of the total cohort were detected. Five of these cancers (4\%) occurred in the treated group and 40 cancers $(5 \%)$ in the untreated group. Four cancers (3\%) occurred in the group of unknown immunosuppression status.

\subsubsection{Types of cancers}

Tables 2 and 3 show the distribution of malignancies. The commonest cancer type observed was colorectal carcinoma (CRC) in 30\% (15 patients which include two with high grade dysplasia of the colon). The skin cancers were the second commonest cancer to occur with 7 cancers in total. There were 2 basal cell carcinomas, 3 melanomas, 1 squamous cell carcinoma, and 1 skin cancer of unknown histology type. All but 1 of the skin cancers (a melanoma in a coloured patient) occurred in Caucasian patients. The third highest cancer types were breast cancer and Non-Hodgkin's lymphoma (5 patients each). Cholangiocarcinoma which is associated with IBD, as an extra-intestinal feature occurred in 2 patients both of whom were dropped due to insufficient or unavailable data.

Table 2: Types of cancer (of interest) stratified by treatment status

\begin{tabular}{|c|c|c|c|c|}
\hline Type of cancer & $\begin{array}{l}\text { Total cancers } \\
(n=49)\end{array}$ & $\begin{array}{l}\text { Cancers in } \\
\text { treated group } \\
(n=5)\end{array}$ & $\begin{array}{l}\text { Cancers in } \\
\text { untreated group } \\
(n=40)\end{array}$ & $\begin{array}{l}\text { Cancers in } \\
\text { unknown } \\
\text { treatment } \\
\text { status }(n=4)\end{array}$ \\
\hline CRC $\%(n)$ & $31 \%(15)$ & $0 \%(0)$ & $80 \%(12)$ & $20 \%(3)$ \\
\hline $\begin{array}{l}\text { Skin (total) \% (n) } \\
\text { BCC } \\
\text { Melanoma } \\
\text { SCC } \\
\text { Unspecified }\end{array}$ & $\begin{array}{l}14.2 \%(7) \\
2 \\
3 \\
1 \\
1\end{array}$ & $\begin{array}{l}29 \%(2) \\
1 \\
1 \\
0 \\
0\end{array}$ & $\begin{array}{l}71 \%(5) \\
1 \\
2 \\
1 \\
1\end{array}$ & $\begin{array}{l}0 \%(0) \\
0 \\
0 \\
0 \\
0\end{array}$ \\
\hline NHL \% $(n)$ & $10 \%(5)$ & $0 \%(0)$ & $80 \%(4)$ & $20 \%(1)$ \\
\hline Breast \% (n) & $10 \%(5)$ & $20 \%(1)$ & $80 \%(4)$ & $0 \%(0)$ \\
\hline Small bowel $\%(n)$ & $4 \%(2)$ & $50 \%(1)$ & $50 \%(1)$ & $0 \%(0)$ \\
\hline $\begin{array}{l}\text { Cholangiocarcinoma } \\
\% \text { (n) }\end{array}$ & $0 \%(0)$ & $0 \%(0)$ & $0 \%(0)$ & $0 \%(0)$ \\
\hline Total (n) & 34 & 4 & 26 & 4 \\
\hline
\end{tabular}


Table 3: Types of other miscellaneous cancer in the cohort stratified by treatment status

\begin{tabular}{|c|c|c|c|c|}
\hline Type of cancer & $\begin{array}{l}\text { Total cancers } \\
(n=49)\end{array}$ & $\begin{array}{l}\text { Cancers in } \\
\text { freated group } \\
(n=5)\end{array}$ & $\begin{array}{l}\text { Cancers in } \\
\text { untreated group } \\
(n=40)\end{array}$ & $\begin{array}{l}\text { Cancers in } \\
\text { unknown } \\
\text { treatment status } \\
(n=4)\end{array}$ \\
\hline Lung \% (n) & $4 \%(2)$ & $0 \%(0)$ & $100 \%(2)$ & $0 \%(0)$ \\
\hline Myeloma \% (n) & $0 \%(0)$ & $0 \%(0)$ & $100 \%(1)$ & $0 \%(0)$ \\
\hline Prostrate \% (n) & $2 \%(1)$ & $0 \%(0)$ & $100 \%(1)$ & $0 \%(0)$ \\
\hline Carcinoid $\%(n)$ & $2 \%(1)$ & $0 \%(0)$ & $100 \%(1)$ & $0 \%(0)$ \\
\hline Stomach \% (n) & $6 \%(3)$ & $0 \%(0)$ & $100 \%(3)$ & $0 \%(0)$ \\
\hline Renal \% (n) & $4 \%(2)$ & $0 \%(0)$ & $100 \%(2)$ & $0 \%(0)$ \\
\hline Sarcoma \%(n) & $2 \%(1)$ & $0 \%(0)$ & $100 \%(1)$ & $0 \%(0)$ \\
\hline Kaposi rectum \%(n) & $2 \%(1)$ & $0 \%(0)$ & $100 \%(1)$ & $0 \%(0)$ \\
\hline Cystic teratoma \% (n) & $2 \%(1)$ & $100 \%(1)$ & $0 \%(0)$ & $0 \%(0)$ \\
\hline Cervix \% (n) & $4 \%(2)$ & $0 \%(0)$ & $100 \%(2)$ & $0 \%(0)$ \\
\hline Total (n) & 15 & 1 & 14 & 0 \\
\hline
\end{tabular}

As there was no CRC or lymphoma in the group of patients who received AZA/6MP, a comparison of the incidence rates for these cancers was not possible. However, the comparison for skin cancers showed an incident rate ratio (IRR) of 2.4 ( $\mathrm{Cl} 0.23-14.5 ; p=0.3336$ ) for those treated compared to those not treated.

\subsection{Bivariate analys is for predicting immunosuppression}

There were several significant differences between the AZAVGMP group and the unexposed group with respect to the explanatory variables and receiving immunosuppression.

\subsubsection{Age}

When the patient characteristics were stratified by treatment status i.e. those treated with AZAJ6MP, those not treated with these agents and those in whom the treatment status was unknown, (Table 1), those that were treated were significantly younger than both those that were not treated $(p=0.001)$ and those in whom treatment data was unavailable $(p=0.0173)$. 
Figure 2: Age stratified by treatment

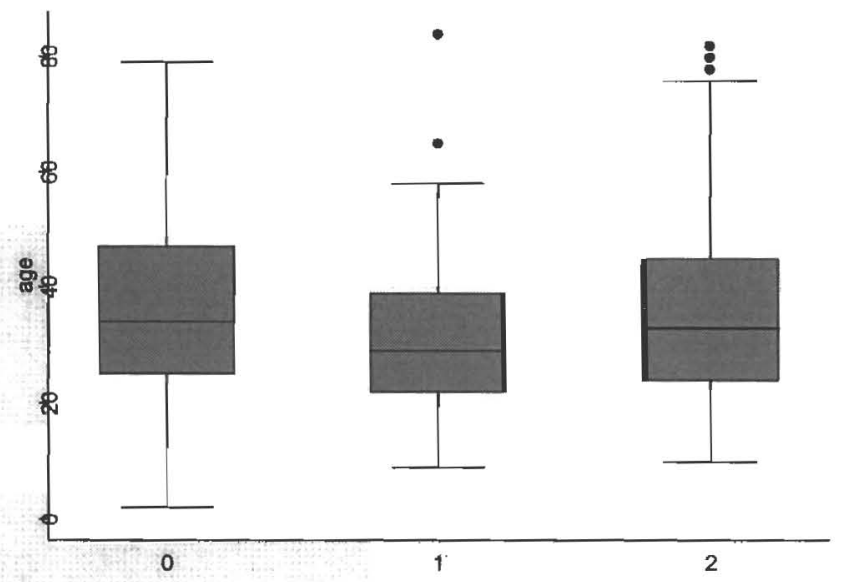

$0=$ no treatment; $1=A Z A / 6 M P ; 2=$ treatment unknown

\subsubsection{Age at diagnosis}

The analysis of the age at IBD diagnosis mirrored that of age, in that those that were treated were younger, with a median age at diagnosis of 29 , compared to their treatment-naïve counterparts with a median age of $34, p=0.0001$ and those in whom the treatment status is unknown, median age $33, p=0.0334$ ).

Figure 3: Age at diagnosis stratified by treatment

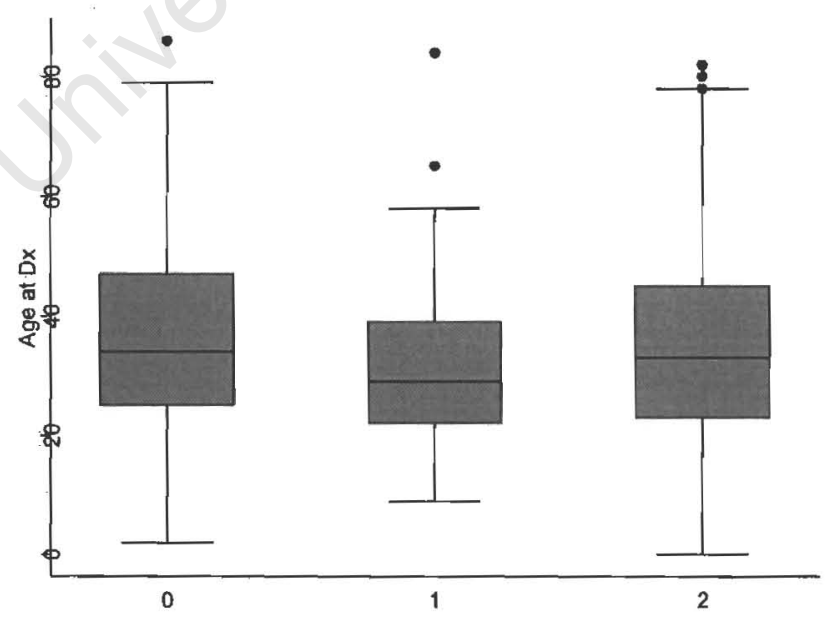

$0=$ no treatment $; 1=A Z A / 6 M P ; 2=$ treatment unknown 


\subsubsection{Gender}

A high percentage of women $(73 \%)$ were in the treatment group compared to a predominant but slightly lower percentage (60\%) in the untreated group, and this was significant $(p=0.003)$.

\subsubsection{Smoking}

The percentage of current smokers was significantly higher in the treated group $(62 \%)$ as compared to the untreated group (37\%). Conversely, the percentage of non-smokers was higher in the untreated group (34\%), than in the treated group $(18 \%)$. These differences were statistically significant $(p<0.001)$. The rate of exsmokers was equal in the two groups.

\subsubsection{Ethnicity}

There was a higher percentage of Coloured patients in the group that was treated $(80 \%)$, compared to that not treated, and interestingly, the percentage of Caucasians in those not treated with AZA6MP was higher (21\%), than in those treated $(14 \%)$, and these differences were significant $(p<0.001)$. The majority of Black patients in the cohort were not treated, and the percentages of those treated and untreated in the Asian population were similar.

\subsubsection{Type of IBD}

In those patients with $\mathrm{CD}$, the majority $(83 \%)$ fell in the treated group, versus $(42 \%)$ in the untreated group. In contrast the majority of patients with UC $(54 \%)$ were not treated. The distribution between the treatment arms was similar for patients with $I C$; all of these were significant $(p<0.001)$.

\subsubsection{Disease extent}

In CD ileo-colitis, the majority of patients were treated (45\%) versus (15\%) in 
the untreated group. Similarly, for CD ileitis and colitis, the majority of patients were treated. In UC however, the majority of patients, with extensive disease, limited disease, or proctitis, were all not treated. These differences were significant $(p=0.000)$

\subsubsection{Malignancy}

In all the treatment groups when compared to each other, there was no difference in cancer.

\subsection{Bivariate analys is for predicting cancer}

A comparison of patient demographic, IBD and treatment characteristics is shown in Table 4 in those that had cancer.

Table 4: Comparison of patients with and without cancer

\begin{tabular}{|c|c|c|c|}
\hline & Malignancy $(n=49)$ & $\begin{array}{l}\text { No Malignancy } \\
(n=1033)\end{array}$ & p-value \\
\hline $\begin{array}{l}\text { Age (years) } \\
\text { Median }\end{array}$ & $42(\operatorname{IQR} 34-60)$ & 33 (IOR 24-45) & 0.002 \\
\hline $\begin{array}{l}\text { Age at diagnosis } \\
\text { (years) } \\
\text { Median }\end{array}$ & $42(\operatorname{lQR} 34-60)$ & 33 (IQR 24-45) & 0.0001 \\
\hline $\begin{array}{l}\text { Gender } \%(n) \\
\text { Female } \\
\text { Male }\end{array}$ & $\begin{array}{l}65 \%(32) \\
35 \%(17)\end{array}$ & $\begin{array}{l}61 \%(629) \\
39 \%(406)\end{array}$ & 0.525 \\
\hline $\begin{array}{l}\text { Smoking (current) \% } \\
(n)\end{array}$ & $32 \%(15)$ & $39 \%(357)$ & 0.683 \\
\hline Ethnicity & $100 \%(49)$ & $100 \%(1031)$ & 0.546 \\
\hline $\begin{array}{l}\text { IBD type \%(n) } \\
\text { UC } \\
\text { CD } \\
\text { IC }\end{array}$ & $\begin{array}{l}50 \%(22) \\
50 \%(24) \\
6 \%(3)\end{array}$ & $\begin{array}{l}50 \%(516) \\
47 \%(490) \\
3 \%(29)\end{array}$ & 0.367 \\
\hline Disease extent $\%(n)$ & $100 \%(49)$ & $100 \%(1033)$ & 0.249 \\
\hline $\begin{array}{l}\text { Treatment status (n) } \\
\text { AZA/6MP } \\
\text { No treatment } \\
\text { Treatment status } \\
\text { unknown }\end{array}$ & $\begin{array}{l}10 \%(5) \\
82 \%(40) \\
8 \%(4)\end{array}$ & $\begin{array}{l}11 \%(118) \\
77 \%(796) \\
12 \%(121) \\
\end{array}$ & 0.705 \\
\hline
\end{tabular}




\subsubsection{Age}

The median age of those with cancer was 42 and those who did not develop a cancer 33. This difference was statistically different $(p=0.0002)$ and this is represented graphically in Figure 4.

Figure 4: Age stratified by cancer

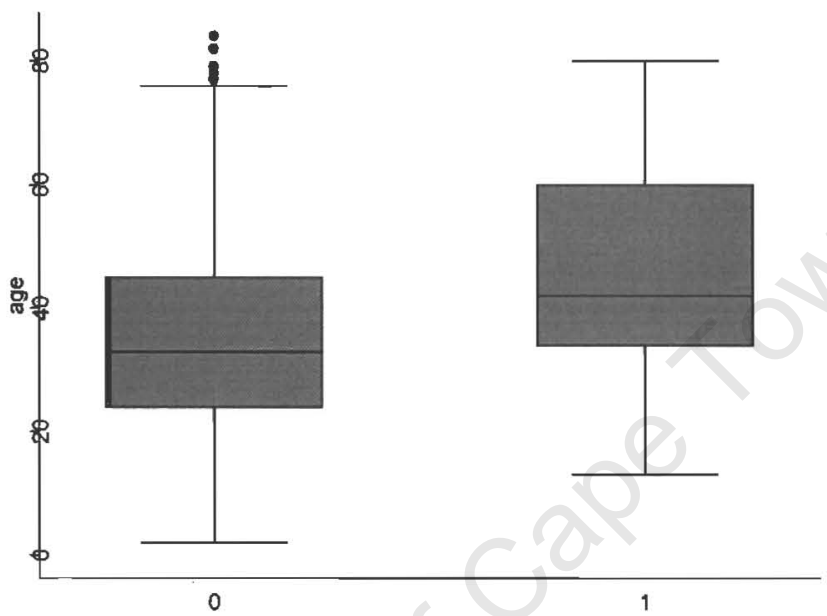

$0=$ no cancer $1=$ cancer

\subsubsection{Age at diagnosis}

Similarly the median age at diagnosis of IBD was statistically different between the cancer groups ( $p=0.0001)$, that is 42 in the group with cancer and 33 in the group without cancer. This is represented graphically in Figure 5. 
Figure 5: Age at diagnosis stratified by cancer

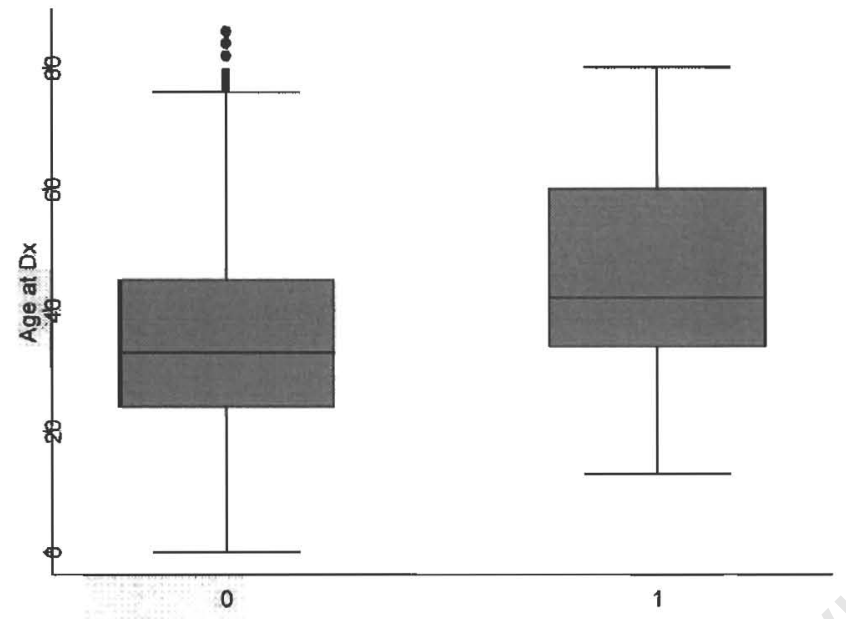

$0=$ no cancer $; 1=$ cancer

\subsubsection{Gender}

Seventeen cancers in the females versus 32 in the males were found, however the difference in the distribution of cancer by gender was not significant, $p=0.525$.,

\subsubsection{Smoking}

The overall smoking history in those with cancer (32\%) was comparable to that in patients without cancer $(39 \%), p=0.683)$.

\subsubsection{Ethnicity}

Overall the ethnicity of patients did not significantly correlate with the development of cancer, $p=0.546$. 
4.3.6. IBD type and disease extent

Of the 49 patients with cancer $65 \%$ were female, and this compares with $61 \%$ of the patients without cancer. The difference in the groups was not significant with a $p=0.367$. Similarly, the extent of disease did not significantly correlate with the occurrence of a cancer, $p=0.249$.

\subsubsection{Immunosuppression}

There was no difference in the incidence of cancer between those treated with those not treated $(p=0.725)$ and those in whom the treatment status is unknown $(p=0.716)$ respectively.

\subsubsection{Duration of treatment}

The median duration of AZA therapy in those with cancer $(n=6)$ was 61 months compared to 24 months in those without cancer $(n=102)$ (Figure 6), however this difference failed to reach statistical difference $(p=0.113)$.

Figure 6: Median duration of AZA (months) stratified by cancer

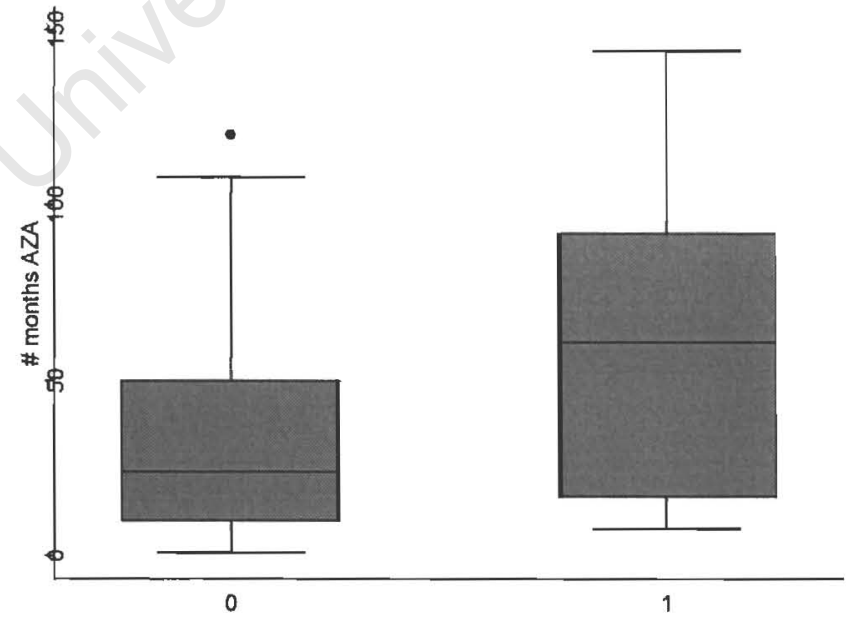

$0=$ no cancer; $1=$ cancer 
No patients treated with 6MP developed a malignancy; in those with no malignancy; the median duration of therapy was 16 months (IQR 6-59). The median period from immunosuppression to the development of a malignancy was 13 months (IQR $4.5-25.5$ ).

\subsubsection{Dose of treatment}

The median cumulative dose of AZA/6MP in those with cancer was 7 grams $(0.27 \mathrm{mg} / \mathrm{kg} / \mathrm{day})$, which was much higher than in those who did not develop a cancer 2 grams $(0.07 \mathrm{mg} / \mathrm{kg} /$ day $)$, and this difference was statistically significant $(p=0.05)$. This is represented graphically in Figure 7 .

Figure 7: Median dose of AZA/6MP (months) stratified by cancer

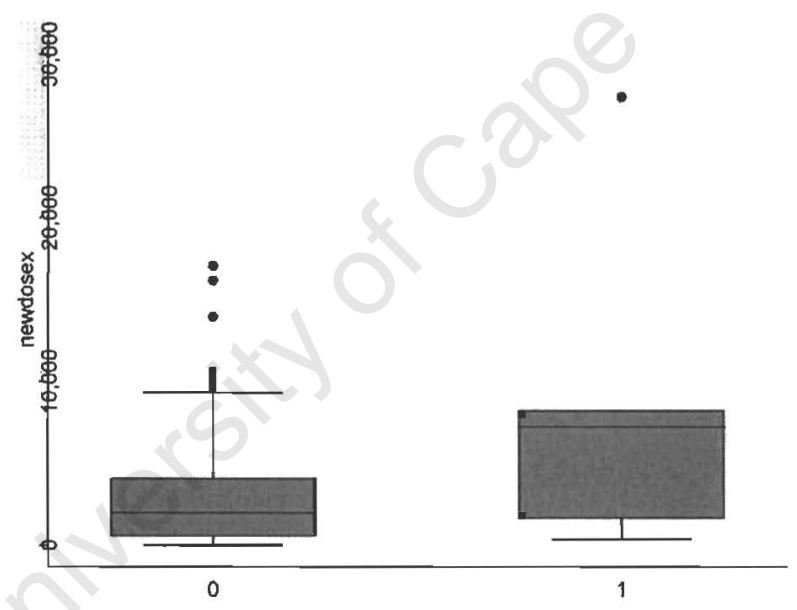

$0=$ no cancer; $1=$ cancer (Dose in milligrams) 


\subsection{Survival estimates of the groups}

Figure 8: Cancer-free survival curves for all cancer the 3 treatment groups

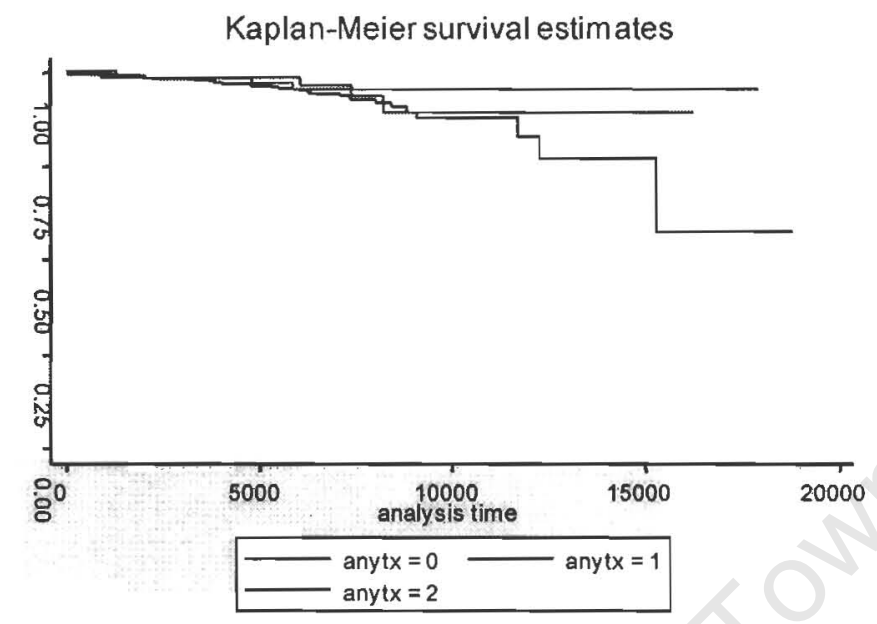

anytx: $0=$ no treatment, $1=A Z A V 6 M P$ and $2=$ unknown treatment

The median survival times between the 3 groups of treatment using KaplanMeier estimates were similar $(p=0.494)$ as shown in Figure 8.

Figure 9: Cancer-free survival curves for CRC in the 3 treatment groups

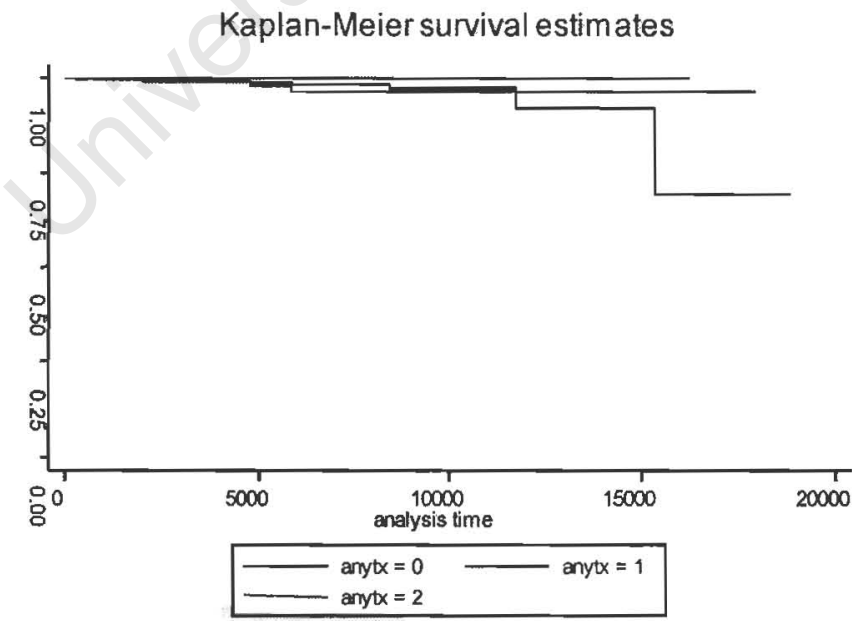

anytx: $0=$ no treatment, $1=A Z A / 6 M P$ and $2=$ unknown treatment 
The median survival for those with CRC in the 3 treatment groups is shown above, and the survival estimates were no different in the 3 groups $(p=0.2631)$.

Figure 10: Cancer-free survival curves for NHL in the 3 treatment groups

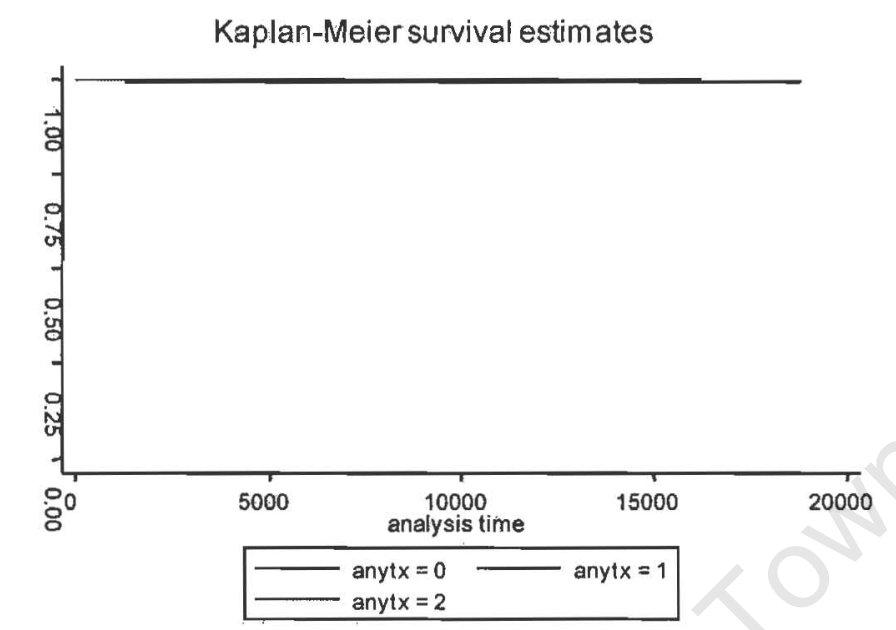

anytx: $0=$ no treatment, $1=A Z A V 6 M P$ and $2=$ unknown treatment

The median survival for those with $\mathrm{NHL}$ in the 3 treatment groups is shown above, and the survival estimates were no different in the 3 groups $(p=0.6853)$.

Figure 11: Survival curves for skin cancer in the 3 treatment groups

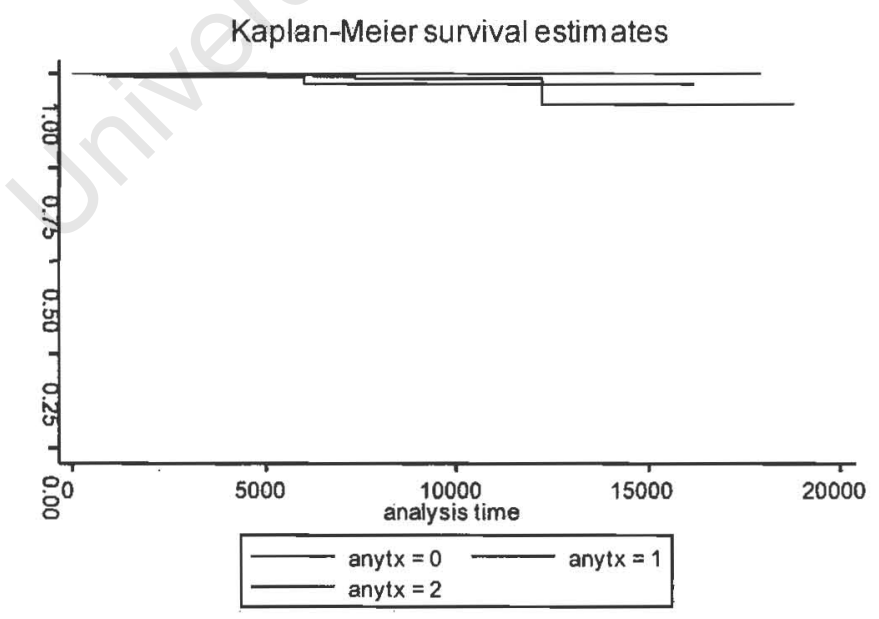

anytx: $0=$ no treatment, $1=A Z A / 6 M P$ and $2=$ unknown treatment 
The median survival for those with skin cancer in the 3 treatment groups is shown above, and the survival estimates were no different in the 3 groups $(p=0.324)$.

\subsection{Models of the relative hazard of cancer during follow-up}

Analysis was undertaken using Cox's proportional hazards model. First, univariate models were constructed to produce the crude (unadjusted) hazard ratio for cancer according to selected covariates. Then, multiple statistical adjustments were carried out using a manual stepwise method for variable selection.

4.5.1. Unadjusted odds ratios for prediction of cancer (Table 5)

\subsubsection{Age}

The association between age and developing a cancer was found to be significant, $\mathrm{HR}=1.04 ; \mathrm{Cl} 1.03-1.07:(\mathrm{p}<0.001)$. Therefore, for every 1 year increase in age (in years) the relative risk of developing a cancer increased 1 -fold.

\subsubsection{Age at diagnosis}

In a similar pattern to age, the age at diagnosis was independently associated with cancer. The lower the age of the patient at diagnosis of IBD, the higher the risk of cancer $(\mathrm{HR}=1.04 ; \mathrm{Cl} 1.03-1.07 ; \mathrm{p}<0.001)$.

\subsubsection{Gender}

Male gender was not found to be independently associated with an increased risk of cancer, $\mathrm{HR}=1.06 \mathrm{Cl} 0.59-1.93 ; p=0.833$. 


\subsubsection{Smoking}

The smoking status of patients, when comparing ex-smokers to current or nonsmokers was not associated with an increased risk of cancer, $\mathrm{HR}=0.97 ; \mathrm{Cl} 0.69$ $-1.35 ; p=0.868$.

\subsubsection{Ethnicity}

The overall association of the ethnic group of patients with the risk of cancer was not statistically significant, $H R=1.29 ; \mathrm{Cl} 0.89=1.87 ; p=0.175$. However, when compared to Coloureds, although not significant, Caucasians had a higher risk of a malignancy, $\mathrm{HR}=1.6 ; \mathrm{Cl} 0.87-2.97 ; \mathrm{p}=0.126$.

\subsubsection{IBD and disease extent}

A diagnosis of CD was not found to be more likely to predict a malignancy, when compared to UC, HR $=1.04 ; \mathrm{Cl} 0.57-1.88 ; p=0.883)$. Similarly, the extent of the disease (compared to a reference group of patients with extensive UC) was not independently associated with malignancy, $H R=1.13 ; \mathrm{Cl} 0.51-3.46, p$ $=0.557$.

\subsubsection{Immune suppression}

Overall the treatment status of the patient whether treated or not was not independently associated with cancer. However although the duration of $A Z A$ was not an independent risk factor for cancer, the dose of AZA approached significance $(p=0.07)$. The dose and duration of $6 \mathrm{MP}$ could not be modelled due to the fact that no patients on 6 MP developed a cancer.

Therefore, in summary, in unadjusted models, an older age and a younger age at diagnosis were the 2 explanatory variables that were independently associated with malignancy. The dose of AZA6MP approached significance in the unadjusted model. 
Table 5: Unadjusted odds ratios for individual predictors of cancer

\begin{tabular}{|c|c|c|c|}
\hline & Hazard ratio & $\begin{array}{c}95 \% \text { Confidience } \\
\text { Interval }\end{array}$ & p-value \\
\hline Age (years) & 1.04 & $1.03-1.07$ & $<0.001$ \\
\hline $\begin{array}{l}\text { Age at diagnosis } \\
\text { (years) }\end{array}$ & 1.04 & $1.03-1.07$ & $<0.001$ \\
\hline $\begin{array}{l}\text { Gender (*female) } \\
\text { Male }\end{array}$ & 1.06 & $0.59-1.93$ & 0.833 \\
\hline $\begin{array}{l}\text { Smoking ("ex- } \\
\text { smoker) } \\
\text { Current smoker }\end{array}$ & 0.97 & $0.69-1.35$ & 0.868 \\
\hline $\begin{array}{l}\text { Ethnicity ("coloured) } \\
\text { White }\end{array}$ & 1.6 & $0.87-2.97$ & 0.126 \\
\hline $\begin{array}{l}\mathrm{IBD}(\text { "UC }) \\
\mathrm{CD}\end{array}$ & 1.04 & $0.57-1.88$ & 0.883 \\
\hline $\begin{array}{l}\text { Disease extent ("UC } \\
\text { extensive) } \\
\text { Other disease extent }\end{array}$ & 1.13 & $0.51-3.46$ & 0.557 \\
\hline $\begin{array}{l}\text { Treatment ("no } \\
\text { AZAGMP) } \\
\text { AZAGMP }\end{array}$ & 0.72 & $0.28-1.82$ & 0.490 \\
\hline $\begin{array}{l}\text { Duration AZA } \\
\text { (months) }\end{array}$ & 1.01 & $0.99-1.03$ & 0.267 \\
\hline Dose AZA (mg) & 1.00 & $0.99-1.00$ & 0.076 \\
\hline
\end{tabular}

*The reference (baseline) category

\subsubsection{Adjusted odds ratios for prediction of cancer (Table 6)}

The first column of Table 6 represents separate models for each of the variables modelled individually. The "best" model containing a single variable, using the BIC parameter was selected. Then in a stepwise fashion variables were added one at a time to the selected best model to assess how the HR's are affected by the addition of a variable.

In model 2 the hazard ratios of each of the variables (added to a model that contains treatment with AZAV6MP) do not change significantly. The association between age $(p=0.000)$ and age at diagnosis $(p=0.000)$ remained significant while the remaining variables showed no association. In model 3 in contrast, the addition of the type of IBD results in a significant increase in the HR for IBD type, although this was not statistically significant $(p=0.06)$. The coefficient for the 
type of IBD increased by more $10 \%$, suggesting a confounding bias.

Table 6: Various models for predicting cancer (adjusted)

\begin{tabular}{|c|c|c|c|c|c|}
\hline $\begin{array}{l}\text { Predictors of } \\
\text { cancer }\end{array}$ & 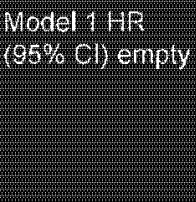 & $\begin{array}{l}\text { Model } 2 \text { ir } \\
\text { ogs, oy } \\
\text { containug } \\
\text { reament }\end{array}$ & 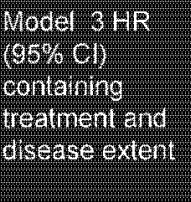 & 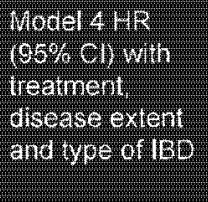 & 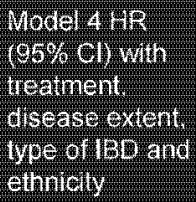 \\
\hline Age & $\begin{array}{c}1.04 \\
(1.03-1.07)\end{array}$ & $\begin{array}{c}1.04 \\
(1.03-1.07)\end{array}$ & $\begin{array}{c}1.05 \\
(1.03-1.07)\end{array}$ & $\begin{array}{c}1.05 \\
(1.03-1.07)\end{array}$ & $\begin{array}{c}1.05 \\
(1.03-1.07)\end{array}$ \\
\hline Age at diagnosis & $\begin{array}{c}1.04 \\
(1.03-1.07)\end{array}$ & $\begin{array}{c}1.04 \\
(1.03-1.07)\end{array}$ & $\begin{array}{c}1.05 \\
(1.03-1.07)\end{array}$ & $\begin{array}{c}1.05 \\
(1.03-1.07)\end{array}$ & $\begin{array}{c}1.05 \\
(1.03-1.07)\end{array}$ \\
\hline Gender & $\begin{array}{c}1.06 \\
(0.59-1.83)\end{array}$ & $\begin{array}{c}1.05 \\
(0.58-1.90)\end{array}$ & $\begin{array}{c}1.02 \\
(0.56-1.84)\end{array}$ & $\begin{array}{c}1.02 \\
(0.56-1.84)\end{array}$ & $\begin{array}{c}1.03 \\
(0.57-1.86)\end{array}$ \\
\hline Smoking & $\begin{array}{c}0.97 \\
(0.69-1.35)\end{array}$ & $\begin{array}{c}1.02 \\
(0.72-1.42)\end{array}$ & $\begin{array}{c}1.01 \\
(0.72-1.43)\end{array}$ & $\begin{array}{c}1.01 \\
(0.72-1.43)\end{array}$ & $\begin{array}{c}1.01 \\
(0.72-1.42)\end{array}$ \\
\hline Ethnicity & $\begin{array}{c}1.29 \\
(0.89-1.87)\end{array}$ & $\begin{array}{c}1.32 \\
(0.91-1.89)\end{array}$ & $\begin{array}{c}1.34 \\
(0.93-1.94)\end{array}$ & $\begin{array}{c}1.34 \\
(0.93-1.94)\end{array}$ & $\begin{array}{c}1.34 \\
(0.92-1.93)\end{array}$ \\
\hline $\mathrm{IBD}$ & $\begin{array}{c}1.28 \\
(0.76-2.15)\end{array}$ & $\begin{array}{c}1.31 \\
(0.78-2.21)\end{array}$ & $\begin{array}{c}2.52 \\
(0.93-6.79)\end{array}$ & $\begin{array}{c}2.52 \\
(0.93-6.79)\end{array}$ & $\begin{array}{c}2.55 \\
(0.96-6.74)\end{array}$ \\
\hline Disease extent & $\begin{array}{c}0.98 \\
(0.84-1.13)\end{array}$ & $\begin{array}{c}0.99 \\
(0.85-1.15)\end{array}$ & $\begin{array}{c}0.79 \\
(0.58-1.06)\end{array}$ & $\begin{array}{c}0.79 \\
(0.58-1.06)\end{array}$ & $\begin{array}{c}0.79 \\
(0.59-1.07)\end{array}$ \\
\hline Treatment & $\begin{array}{c}0.76 \\
(0.47-1.21)\end{array}$ & $\begin{array}{c}0.75 \\
(0.47-1.21)\end{array}$ & $\begin{array}{c}0.77 \\
(0.47-1.26)\end{array}$ & $\begin{array}{c}0.77 \\
(0.47-1.26)\end{array}$ & $\begin{array}{c}0.76 \\
(0.47-1.23)\end{array}$ \\
\hline
\end{tabular}

\subsection{Models of the relative odds of receiving immunosuppression}

The predictors for being treated with immunosuppression were assessed.

4.6.1. Unadjusted odds ratios for prediction of immunosuppression (Table 7)

Overall the odds ratios for age $(p=0.122)$, age at diagnosis $(p=0.106)$, and smoking $(p=0.865)$ were not independently associated with immunosuppression. Gender $(O R=1.54 ; \mathrm{Cl} 1.03-2.29 ; p=0.035)$, the ethnic group $(O R=0.48 ; C l$ $0.28-0.81, p=0.006)$, type of IBD (OR $=3.15 ; \mathrm{Cl} 2.23-4.44 ; \mathrm{p}=0.000)$, extent of disease $(O R=1.21 ; \mathrm{Cl} 1.09-1.32 ; p=0.000)$ and were associated with treatment with AZA6MP. Males when compared to women were more 1.5 times more likely to be treated with AZA 6MP, and as compared to Coloureds, White patients were less likely to be treated with thiopurines and this was significant. Those patients with UC, those with CD were 5 times more likely to receive AZAVGMP $(p=0.000)$. Regarding the extent of the disease, as compared to patients with CD ileo-colitis, those with UC extensive disease had a higher chance of receiving AZA/6MP (HR 
$3.5 ; \mathrm{Cl} 1.9-6.5, \mathrm{p}=0.000)$.

Table 7: Unadjusted odds ratios for individual predictors of immunosuppression

\begin{tabular}{|c|c|c|c|}
\hline & Ilazaro ratio & $95 \%$ Confidence Interval & p-value \\
\hline Age (vears) & 0.99 & $0.96-1.00$ & 0.122 \\
\hline $\begin{array}{l}\text { Age at diagnosis } \\
\text { (years) }\end{array}$ & 0.99 & $0.97-1.00$ & 0.106 \\
\hline $\begin{array}{l}\text { Gender (female) } \\
\text { Male }\end{array}$ & 1.54 & $1.03-2.29$ & 0.035 \\
\hline $\begin{array}{l}\text { Smoking ("ex-smoker) } \\
\text { Current smoker }\end{array}$ & 1.14 & $0.67-1.95$ & 0.624 \\
\hline $\begin{array}{l}\text { Ethnicity ("coloured) } \\
\text { White }\end{array}$ & 0.48 & $0.28-0.81$ & 0.006 \\
\hline 180 (overall) & 3.15 & $2.23-4.44$ & 0.000 \\
\hline $\begin{array}{l}\text { Disease extent } \\
\text { (overall) }\end{array}$ & 1.21 & $1.09-1.32$ & 0.000 \\
\hline Cancer & 0.90 & $0.37-2.20$ & 0.819 \\
\hline
\end{tabular}

* baseline category

4.6.2. Adjusted odds ratios for prediction of immunosuppression

Variable selection was done in the same manner as for cancer. Effectively there was no change observed in the strength of association when various models were generated. 


\section{Discussion}

\subsection{Summary of the findings}

This study is a hospital-based retrospective review of the incidence of cancer in patients on AZA and 6MP. In this study the risk of any cancer was not significantly different in those that received thiopurine therapy as compared to those who were not treated and those whose treatment status was unknown. Furthermore, excluding the cases of CRC, which are most likely associated with IBD, the highest occurrence of cancer was that of the skin. The factors that were shown to be independently associated with an increased risk of malignancy were an older age of the patient and a younger age at diagnosis of IBD.

\subsection{Potential reasons for the findings}

\subsubsection{Immunosuppression}

The majority of the patients were not on immunosuppression (77\%), and in those on treatment both the duration (median 24 months) and doses of treatment (median dose AZA/6MP $0.07 \mathrm{mg} / \mathrm{kg} /$ day) tended were low when compared to transplant recipients. This suggests that unlike in developed countries, a more conservative approach towards prescribing AZA/6MP is adopted at our facility, Based on a weight-based dosing regimen, optimum doses for AZA are considered to be $2-2.5 \mathrm{mg} / \mathrm{kg} /$ day and for $6 \mathrm{MP} 1.5-2.0 \mathrm{mg} / \mathrm{kg} /$ day. Therefore, in our cohort the majority of patients had not been effectively established on a stable dose of AZA/6MP hence the low doses. In most studies and clinical trials, patients who have been established on immunosuppression at the optimum dose for at least 3 to 6 months are enrolled.

$A Z A$ and $6 M P$ were used mainly for $C D$, in its more extensive form (ileo-colitis) indicative of the currentprescribing tendencies and the place of immunosuppressive therapy in IBD (i.e. AZA/6MP are not the initial therapy for IBD and are used for more aggressive disease patterns). 
AZA and 6MP were also used for patients that were younger and those in whom the diagnosis was made at an earlier age. An earlier age of diagnosis in IBD patients treated with AZA/6MP was also noted in a previous study (Fraser et al., 2002). Early onset of disease and, therefore, longer duration of chronic inflammation appear to influence the development of colon cancer (Bernstein et al., 1996), thus by inference due to longer periods of inflammation, these patients probably have more aggressive disease and hence predict the use of immunosuppression. White patients were less likely to be treated with AZA/6MP than either coloureds or Blacks and yet the majority of skin cancer occurred in this group. This finding suggests that the increased risk of skin cancer in Whites is not related to immunosuppression, but likely due to confounding factors such as exposure to UV light. Being able to quantify exposure to UV light and compare it to those not exposed in the IBD cohort would be invaluable in untangling the individual and interactive effects of both UV light and treatment with AZA/6MP.

\subsubsection{Patient characteristics}

The overall patient characteristics of the 3 patient groups were different; this finding may explain the lack of association between the use of AZA/6MP and cancer. Those that were treated were younger, were diagnosed earlier with IBD, had a higher percentage of current smokers and the majority had $C D$. Combined all these factors could both individually and in concert result in higher incidences of cancer overall. This, however, was not the case in this study. There may be unstudied group effects or confounders that may be at play to explain this lack of association. More likely an explanation however, could be the small sample size of the cohort.

\subsubsection{Duration and dose of AZA/6MP}

This study did not show a difference in the incidence of cancer between those treated and those not treated. However when doing a sub-group analysis in those that developed cancer, although both the duration (median 61 months) and doses of treatment (median $0.27 \mathrm{mg} / \mathrm{kg} / \mathrm{day}$ ) were higher than in the cohort as a whole, providing circumstantial evidence that these 2 factors are correlated to increased incidence of malignancy, the overall effect was null in this cohort. This could be 
explained by the fact that even in those that developed a cancer, the doses are still significantly below the recommended daily dose. The association between higher doses of immunosuppression, for longer periods and the development of cancer has been clearly shown in patients with solid organ transplants, who typically are on higher doses of immunosuppression, and for longer periods.

\subsubsection{Small numbers/Insufficient power}

The lack of difference in this study may be explained by the lack of sufficient power of the study. A sample size calculation prior to commencing the study was not possible as the study size was fixed by the patient numbers in the dataset. However, a post-hoc power calculation showed that this study had a power of only $43 \%$ to detect a difference of $7 \%$ in malignancy in the treated and untreated groups, with $95 \% \mathrm{Cl}$.

\subsection{Adding to current knowledge}

These results are important because this is the first study (to our knowledge) to be conducted in Sub-Saharan Africa/Africa which examines this association. Despite the exposure of our patients to generally sunny weather conditions and thus UV light, this study failed to show an association between AZA6MP treatment and any cancer, and more specifically, skin cancer. The results of the studies conducted thus far have been conflicting, however, overall the association between the use of AZA $6 M P$ and the risk cancer appears to be low. This is reflected in that the prescribing policies have not changed as a result of the positive studies; both AZA and $6 \mathrm{MP}$ form part of the integral management of patients with IBD. Furthermore, specific recommendations for screening and monitoring of patients on these medications have not been tabled; punctuating the collective consensus of the safety of these medications. Moreover, the survival estimates for patients treated and those not treated were similar. Therefore, this study adds to this body of evidence of the safety of these medications, notwithstanding the relatively shorter periods of exposure to the thiopurines. 


\subsection{Differences and similarities with other studies}

This study is similar in the outcome to many other studies done previously, including a meta-analysis (Masunaga et al, 2007), where an increased incidence of cancers was not demonstrated in IBD cohorts. In this study only 5 lymphomas (NHL) in the total cohort were discovered. Four of these cancers occurred in patients in the untreated group, and 1 in a patient whose treatment status is unknown. It has been shown that overall lymphomas are associated with both high doses of immunosuppression as well as long durations of therapy, and in our study, relatively low doses were used and over shorter periods. This finding is in stark contrast to a study by Farrell et al, 2000, which showed that patients with IBD on immunosuppression had ( 59 times) higher risk for developing a lymphoma than the general population. This extra-ordinary result may be explained by the fact that patients with IBD were being compared to the general population, and thus IBD may have confounded and inflated the association between immunosuppression and NHL and as stated earlier, one of the patients was treated with both MTX and CSA. In this study, in contrast, all patient groups had underlying IBD, therefore, it may be that the risk of lymphoma in the groups was similar, and therefore failed to show an increased risk in those treated.

When CRC's are excluded from the data (CRC's have been shown unequivocally to be associated with $\mid B D$ ) and this may have accounted for this increase in this cohort, skin cancer was the commonest cancer to occur. The South African National Cancer Registry reports an overall population ratio of $\mathrm{BCC}: \mathrm{SCC}$ of $3: 1$ (Sitas et al., 1998). In this study the ratio of BCC:SCC in the untreated (control) group was 1:1 and in the treated group 1:0. This study failed to show a reversed $\mathrm{BCC}$ :SCC ratio in those that were treated which contrasts to a finding that was demonstrated previously in azathiorine-treated non-IBD patients (Sheil et al., 1992).

\subsection{Potential biases}

\subsubsection{Selection bias}

The majority of these patients had more extensive IBD, which possibly reflects 
the referral bias; the facility at which these patients were treated is a tertiary sub-specialised unit. This bias however is counter-balanced by the fact that the controls had IBD and were also from the same facility.

\subsubsection{Detection}

The diagnosis of cancer in this study was made from obtaining patient clinical and pathological records. Therefore, if the patients were being managed elsewhere for their cancers, this could have resulted in an underestimation of the occurrence of new cancers in this cohort. Additionally, due to the fact that 198 patient records were excluded for reasons of inadequate available data, particularly, that on the use of immunosuppresssion, cancers occurring in this group would be missed leading to an underestimation of the risk of cancer overall.

\subsubsection{Attrition}

One hundred and seventy six patients were lost to follow up during the period of the study, and of these 7 cancers were picked up from their clinical and pathological notes. This translates to a rate of $4 \%$ versus $4.5 \%$ in the cohort. Therefore, attrition bias is unlikely to have contributed to the study results as these rates of cancer are similar in those followed up to the end of the study, and those censored.

\subsection{Strengths and limitations}

The strength of the study lies in that it is the first study in Sub-Saharan Africa to evaluate the association between immunosuppression and cancer. In particular, although skin cancer was not found to be increased, it supports the notion that although a synergy between UVA and AZA has been shown in clinical practice in patients on moderate doses of AZA, the risk of cancer is low. These results are consistent with those of the most recent meta-analysis (Masunaga 2007) which included nine cohort studies in the analysis and failed to show an increased risk in patients with IBD.

The main limitation of the study was its retrospective nature, and the 
attendant problems of missing data. As a result of this, although 246 patients were on immunosuppression in this cohort, only 123 records could be analysed, furthermore 198 records were excluded for reasons of missing or incomplete data. The exclusion of these records led to a reduction in the sample size, which has had a significant impact on the results and thus the outcome. Secondly, the diagnosis of cancer was made from patient records (clinical and pathological), and the accuracy of these records was not objectively assessed and/or validated.

\subsection{Recommendations}

It can thus be recommended that IBD patients on AZA or 6MP be treated for as long as therapy is required and that in those with personal or family histories that may increase their risk, more intensive monitoring and surveillance for cancer is undertaken, especially, after treatment with these agents over a long period. Generalised screening for cancers in this cohort cannot be currently recommended, thus surveillance for cancer should be individualised and tailored to specific patient risk and needs.

\subsection{Influence on policy}

Overall in the literature thiopurines seem to be safe and the overall risk of cancer is considered to be low. Therefore, the risk of cancer is by far outweighed by the benefit and relative safety of these agents. It is unlikely, given the body of evidence accumulated thus far, that the prescribing policies will change.

\subsection{Future research}

Two meta-analyses have already been conducted yielding different results, and other numerous studies have been concluded. The overall risk of cancer appears to be small due to relatively smaller doses and shorter periods of treatment. Both meta-analyses had different end-points which make it difficult to compare the studies head-to-head. A meta-analysis incorporating all studies done to date and stratifying the period to before 1990 and after 1990 , could prove to be useful to definitively answer this question. It could be determined by this stratification whether prescribing practices may have influenced the results in the older studies 
or not. This meta-analysis would also evaluate all types of immunosuppression, with primary end-points of lymphoma and skin cancer and not all cancer in IBD patients.

\section{Conclusion}

This study failed to show an association between the use of thiopurines and cancer. Furthermore, it failed to show a significant association between use of AZA/6MP and skin cancer. Although the patients in this study tended to be on lower doses of therapy and durations when compared to transplant recipients, it is unlikely that these factors accounted for the negative results. Skin cancer occurred mainly in White patients; thus it is more likely that these cancers were due to ethnic factors, as well as exposure to UVA, rather than the use of immunosuppressives. Therefore, this study is consistent with many other studies that have failed to show an association, and adds to the body of evidence that, effectively, overall, these agents can be considered to be safe, particularly in IBD patients. 


\section{References}

Aithal, G.P. \& Mansfield, J.C. 2001, "Review article: the risk of lymphoma associated with inflammatory bowel disease and immunosuppressive treatment", Alimentary Pharmacology \& Therapeutics, vol. 15, no. 8, pp. 1101-1108.

Akash A, Patel MD, RobertA, Swerlick MD, Calvin O. McCall 2006, "Azathioprine in dermatology: The past, the present, and the future" , , pp. 369.

AlHadithy, A.F., de Boer, N.K., Derijks, L.J., Escher, J.C., Mulder, C.J. \& Brouwers, J.R. 2005, "Thiopurines in inflammatory bowel disease: pharmacogenetics, therapeutic drug monitoring and clinical recommendations", Digestive and liver disease : official journal of the Italian Society of Gastroenterology and the Italian Association for the Study of the Liver, vol. 37, no. 4, pp. 282-297.

Asten, P., Barrett, J. \& Symmons, D. 1999, "Risk of developing certain malignancies is related to duration of immunosuppressive drug exposure in patients with rheumatic diseases", The Journal of rheumatology, vol. 26, no. 8 , pp. 1705-1714.

Austin, A.S. \& Spiller, R.C. 2001, "Inflammatory bowel disease, azathioprine and skin cancer: case report and literature review", European journal of gastroenterology \& hepatology, vol. 13, no. 2, pp. 193-194.

Baumgart, D.C. \& Sandborn, W.J. 2007, "Inflammatory bowel disease: clinical aspects and established and evolving therapies", Lancet, vol. 369, no. 9573, pp. 1641-1657.

Bernstein, C.N. 2000, "Neoplastic and other complications of inflammatory bowel disease", Current gastroenterology reports, vol. 2, no. 6, pp. 451-459.

Bottomley, W.W., Ford, G., Cunliffe, W.J. \& Cotterill, J.A. 1995, "Aggressive squamous cellcarcinomas developing in patients receiving long-termazathioprine", 
The British journal of dermatology, vol. 133, no. 3, pp. 460-462.

Bouhnik, Y., Lemann, M., Mary, J.Y., Scemama, G., Tai, R., Matuchansky, C., Modigliani, R. \& Rambaud, J.C. 1996, "Long-term follow-up of patients with Carter, M.J., Lobo, A.J., Travis, S.P.L. 2004, "Guidelines for the management of inflammatory bowel disease in adults", Gut, 53 (suppl V): v1-v16.doi:10.1136/ gut.2004.043377.

Crohn's disease treated with azathioprine or 6-mercaptopurine", Lancet, vol. 347 , no. 8996 , pp. 215-219.

Confavreux, C., Saddier, P., Grimaud, J., Moreau, T., Adeleine, P. \& Aimard, G. 1996, "Risk of cancer from azathioprine therapy in multiple sclerosis: a casecontrol study", Neurology, vol. 46, no. 6, pp. 1607-1612.

Connell, W.R., Kamm, M.A., Dickson, M., Balkwill, A.M., Ritchie, J.K. \& Lennard-

Jones, J.E. 1994, "Long-term neoplasia risk after azathioprine treatment in inflammatory bowel disease", Lancet, vol. 343, no. 8908, pp. 1249-1252.

Dalton, A., Curtis, D. \& Harrington, C.I. 1990, "Synergistic effects of azathioprine and ultraviolet light detected by sister chromatid exchange analysis", Cancer genetics and cytogenetics, vol. 45, no. 1, pp. 93-99.

Dayharsh, G.A., Loftus, E.V.,Jr, Sandborn, W.J., Tremaine, W.J., Zinsmeister, A.R., Witzig, T.E., Macon, W.R. \& Burgart, L.J. 2002, "Epstein-Barr virus-positive lymphoma in patients with inflammatory bowel disease treated with azathioprine or 6-mercaptopurine", Gastroenterology, vol. 122, no. 1, pp. 72-77.

de Boer, N.K., van Bodegraven, A.A., Jharap, B., de Graaf, P. \& Mulder, C.J. 2007, "Drug Insight: pharmacology and toxicity of thiopurine therapy in patients with IBD", Nature clinical practice.Gastroenterology \& hepatology, vol. 4, no. 12, 
pp. 686-694.

Ekbom,A., Helmick, C., Zack, M.\&Adami, H.O.1991, "Extracolonicmalignancies in inflammatory bowel disease", Cancer, vol. 67, no. 7, pp. 2015-2019.

Farrell, R.J., Ang, Y., Kileen, P., O'Briain, D.S., Kelleher, D., Keeling, P.W. \& Weir, D.G. 2000, "Increased incidence of non-Hodgkin's lymphoma in inflammatory bowel disease patients on immunosuppressive therapy but overall risk is low", Gut, vol. 47 , no. 4 , pp. 514-519.

Fraser, A.G., Orchard, T.R., Robinson, E.M. \& Jewell, D.P. 2002, "Long-term risk of malignancy after treatment of inflammatory bowel disease with azathioprine", Alimentary Pharmacology \& Therapeutics, vol. 16, no. 7, pp. 1225-1232.

Gaya, S.B., Rees, A.J., Lechler, R.I., Williams, G. \& Mason, P.D. 1995, "Malignant disease in patients with long-term renal transplants", Transplantation, vol. 59, no. 12, pp. 1705-1709.

Gillen, C.D., Andrews, H.A., Prior, P. \& Allan, R.N. 1994, "Crohn's disease and colorectal cancer", Gut, vol. 35, no. 5, pp. 651-655.

Glazier, K.D., Palance, A.L., Griffel, L.H. \& Das, K.M. 2005, "The ten-year single-center experience with 6-mercaptopurine in the treatment of inflammatory bowel disease", Journal of clinical gastroenterology, vol. 39, no. 1, pp. 21-26.

Glick, S.N. 1991. "Gastric carcinoma in patients with Crohn disease: report of four cases". AJR Am J Roentgenol, vol. 157, no. 2, pp. 311-314.

Greenstein, A.J., Gennuso, R., Sachar, D.B., Heimann, T., Smith, H., Janowitz, H.D. \& Aufses, A.H.,Jr 1985, "Extraintestinal cancers in inflammatory bowel

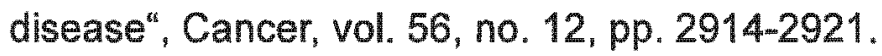

Gyde, S.N., Prior, P., Macartney, J.C., Thompson, H., Waterhouse, J.A., Allan, R.N. 1980, "Malignancy in Crohn's disease", Gut, vol 21, no. 12, pp. $1024-1029$. 
Jensen, P., Hansen, S., Moller, B., Leivestad, T., Pfeffer, P., Geiran, O., Fauchald, P. \& Simonsen, S. 1999, "Skin cancer in kidney and heart transplant recipients and different long-term immunosuppressive therapy regimens", Journal of the American Academy of Dermatology, vol. 40, no. 2 Pt 1, pp. 177-186.

Jess, T., Gamborg, M., Matzen, P., Munkholm, P. \& Sorensen, T.I. 2005, "Increased risk of intestinal cancer in Crohn's disease: a meta-analysis of population-based cohort studies", The American Journal of Gastroenterology, vol. 100 , no. 12 , pp. 2724-2729.

Jess, T., Winther, K.V., Munkholm, P., Langholz, E. \& Binder, V. 2004, "Intestinal and extra-intestinal cancer in Crohn's disease: follow-up of a populationbased cohort in Copenhagen County, Denmark", Alimentary Pharmacology \& Therapeutics, vol. 19, no. 3, pp. 287-293.

Jones, J.L. \& Loftus, E.V.,Jr 2007, "Lymphoma risk in inflammatory bowel disease: is it the disease or its treatment?", Inflammatory bowel diseases, vol. 13 , no. $10, \mathrm{pp} .1299-1307$.

Kandiel, A., Fraser, A.G., Korelitz, B.I., Brensinger, C. \& Lewis, J.D. 2005, "Increased risk of lymphoma among inflammatory bowel disease patients treated with azathioprine and 6-mercaptopurine", Gut, vol. 54, no. 8, pp. 1121-1125.

Karlen, P., Lofberg, R., Brostrom, O., Leijonmarck, C.E., Hellers, G. \& Persson, P.G. 1999, "Increased risk of cancer in ulcerative colitis: a population-based cohort study", The American Journal of Gastroenterology, vol. 94, no. 4, pp. 1047-1052.

Karran, P. 2006, "Thiopurines, DNA damage, DNA repair and therapy-related cancer", British medical bulletin, vol. 79-80, pp. 153-170.

Katz, J.A. 2007, "Management of inflammatory bowel disease in adults", Journal of digestive diseases, vol. 8 , no. 2, pp. 65-71. 
Kinlen, L.J. 1985, "Incidence of cancer in rheumatoid arthritis and other disorders after immunosuppressive treatment", The American Journal of Medicine, vol. 78 , no. 1 A, pp. 44-49.

Kishikawa, H., Ichikawa, Y., Yazawa, K., Hanafusa, T., Fukunishi, T., Ebisui, C., Okuyama, A. \& Nagano, S. 1998, "Malignant neoplasm in kidney transplantation", International journal of urology : official journal of the Japanese Urological Association, vol. 5 , no. 6 , pp. 521-525.

Korelitz, B.I., Mirsky, F.J., Fleisher, M.R., Warman, J.I., Wisch, N. \& Gleim, G.W. 1999, "Malignant neoplasms subsequent to treatment of inflammatory bowel disease with 6-mercaptopurine", The American Journal of Gastroenterology, vol. 94 , no. 11 , pp. 3248-3253.

Kronberger, I.E., Graziadei, I.W. \& Vogel, W.2006, "Smallboweladenocarcinoma in Crohn's disease: a case report and review of literature", World journal of gastroenterology: WJG, vol. 12, no. 8, pp. 1317-1320.

Kwon, J.H. \& Farrell, R.J. 2005, "The risk of lymphoma in the treatment of inflammatory bowel disease with immunosuppressive agents", Critical reviews in oncology/hematology, vol. 56, no. 1, pp. 169-178.

Lakatos, L. \& Lakatos, P.L. 2007, "Medical therapy of inflammatory bowel diseases: ulcerative colitis", Orvosi hetilap, vol. 148, no. 25, pp. 1163-1170.

Lakatos, L. \& Lakatos, P.L. 2006, "Management of inflammatory bowel diseases in Eastern Europe", Postgraduate medical journal, vol. 82, no. 966, pp. 270-273.

Lamers, C.B., Griffioen, G., van Hogezand, R.A. \& Veenendaal, R.A. 1999, "Azathioprine: an update on clinical efficacy and safety in inflammatory bowel disease", Scandinavian journal of gastroenterology.Supplement, vol. 230, pp. $111-115$. 
Le Marc'hadour, F., Bost, F., Peoc'h, M., Roux, J.J., Pasquier, D. \& Pasquier, B. 1994, "Carcinoid tumour complicating inflammatory bowel disease. A study of two cases with review of the literature", Pathology, research and practice, vol. 190 , no. 12, pp. 1185-92; discussion 1193-200.

Lee, S.W., Sonoda, T. \& Milsom, J.W. 2005, "Three cases of adenocarcinoma following restorative proctocolectomy with hand-sewn anastomosis for ulcerative colitis: a review of reported cases in the literature", Colorectal disease : the official journal of the Association of Coloproctology of Great Britain and Ireland, vol. 7, no. 6, pp. 591-597.

Lennard, L., Thomas, S., Harrington, C.I. \& Maddocks, J.L. 1985, "Skin cancer in renal transplant recipients is associated with increased concentrations of 6-thioguanine nucleotide in red blood cells", The British journal of dermatology, vol. 113, no. 6, pp. $723-729$.

Lewis, J.D., Bilker, W.B., Brensinger, C., Deren, J.J., Vaughn, D.J. \& Strom, B.L. 2001, "Inflammatory bowel disease is not associated with an increased risk of lymphoma", Gastroenterology, vol. 121, no. 5, pp. 1080-1087.

Lewis, J.D., Schwartz, J.S. \& Lichtenstein, G.R. 2000, "Azathioprine for maintenance of remission in Crohn's disease: benefits outweigh the risk of lymphoma", Gastroenterology, vol. 118, no. 6, pp. 1018-1024.

Li, A.C., Warnakulasuriya, S. \& Thompson, R.P. 2003, "Neoplasia of the tongue in a patient with Crohn's disease treated with azathioprine: case report", European journal of gastroenterology \& hepatology, vol. 15, no. 2, pp. 185-187.

Lloveras, J.J., Cointault, O., Huyn, A., Boyer, M., Fournial, G., Rostaing, L., Durand, D. \& Suc, J.M. 1995, "Decreased incidence of Iymphomas after heart transplantation under low-dose immunosuppression", Transplantation proceedings, vol. 27 , no. 2 , pp. 1778.

Mackey, A.C., Green, L., Liang, L.C., Dinndorf, P. \& Avigan, M. 2007, 
"Hepatosplenic T cell lymphoma associated with infliximab use in young patients treated for inflammatory bowel disease", Journal of pediatric gastroenterology and nutrition, vol. 44, no. 2, pp. 265-267.

Masunaga, Y., Ohno, K., Ogawa, R., Hashiguchi, M., Echizen, H. \& Ogata, H. 2007, "Meta-analysis of risk of malignancy with immunosuppressive drugs in inflammatory bowel disease", The Annals of Pharmacotherapy, vol. 41, no. 1, pp. 21-28.

Masunaga, Y., Ohno, K., Ogawa, R., Hashiguchi, M., Echizen, H. \& Ogata, H. 2007, "Meta-analysis of risk of malignancy with immunosuppressive drugs in inflammatory bowel disease", The Annals of Pharmacotherapy, vol. 41, no. 1, pp. 21-28.

Munkholm, P., Langholz, E., Davidsen, M. \& Binder, V. 1993, "Intestinal cancer risk and mortality in patients with Crohn's disease", Gastroenterology, vol. 105, no. 6, pp. 1716-1723.

Nakao, K., Tsunoda, A., Shimizu, Y., Takenaka, K., Morohara, K., Suzuki, N., Yamazaki, K., Aoki, T., Hoshino, M., Kusano, M., Kitadai, E., Kurihara, T., Takeuchi, Y. \& Imawari, M. 2005, "Development of hepatocellular carcinoma following treatment with 6-mercaptopurine for ulcerative colitis: investigation of chromosomal aberration by comparative genomic hybridization", International journal of clinical oncology / Japan Society of Clinical Oncology, vol. 10, no. 4, pp. 281-284.

Nascimbeni, R., Villanacci, V., Di Fabio, F., Gavazzi, E., Fellegara, G. \& Rindi, G. 2005, "Solitary microcarcinoid of the rectal stump in ulcerative colitis", Neuroendocrinology, vol. 81 , no. 6 , pp. 400-404.

Phillips, T., Salisbury, J., Leigh, I. \& Baker, H. 1987, "Non-Hodgkin's lymphoma associated with long-term azathioprine therapy", Clinical and experimental dermatology, vol. 12 , no. 6 , pp. 444-445.

Present, D.H. 1993, "Cyclosporine and other immunosuppressive agents: 
current and future role in the treatment of inflammatory bowel disease", The American Journal of Gastroenterology, vol. 88, no. 5, pp. 627-630.

Present, D.H., Meltzer, S.J., Krumholz, M.P., Wolke, A. \& Korelitz, B.I. 1989, "6-Mercaptopurine in the management of inflammatory bowel disease: short- and long-term toxicity", Annals of Internal Medicine, vol. 111, no. 8, pp. 641-649.

Roberts, P.L., Veidenheimer, M.C., Cassidy, S. \& Silverman, M.L. 1989, "Adenocarcinoma arising in an ileostomy. Report of two cases and review of the literature", Archives of surgery (Chicago, III.: 1960), vol. 124, no. 4, pp. 497-499.

Sheil, A.G., Disney, A.P. , Mathew, T.G., Amiss, N. \& Excell, L. 1992, "Malignancy following renal transplantation", Transplantation proceedings, vol. 24 , no. 5 , pp. 1946-1947.

Silman, A.J., Petrie, J., Hazleman, B. \& Evans, S.J. 1988, "Lymphoproliferative cancer and other malignancy in patients with rheumatoid arthritis treated with azathioprine: a 20 year follow up study", Annals of the Rheumatic Diseases, vol. 47, no. 12, pp. 988-992.

Sleisenger and Fordtran's 2006, in Gastrointestinal and Liver Disease Pathophysiology/Diagnosis/Management, 8th edn, Saunders Elsevier, Philadelphia, pp. 2459-2483.

Tan, C.W., Wilson, G.E., Howat, J.M. \& Shreeve, D.R. 2001, "Rectal lymphoma in ulcerative colitis treated with azathioprine". European joumal of gastroenterology \& hepatology, vol. 13 , no. 8 , pp. $989-992$.

Tiede, I., Fritz, G., Strand, S., Poppe, D., Dvorsky, R., Strand, D., Lehr, H.A., Wirtz, S., Becker, C., Atreya, R., Mudter, J., Hildner, K., Bartsch, B., Holtmann, M., Blumberg, R., Walczak, H., Iven, H., Galle, P.R., Ahmadian, M.R. \& Neurath, M.F. 2003, "CD28-dependent Rac1 activation is the molecular target of azathioprine in primary human CD4+ T lymphocytes", The Journal of clinical investigation, vol. 111 , no. 8, pp. 1133-1145. 
Timmer, A., McDonald, J.W. \& Macdonald, J.K. 2007, "Azathioprine and 6-mercaptopurine for maintenance of remission in ulcerative colitis", Cochrane database of systematic reviews (Online), vol. (1), no. 1, pp. CD000478.

West, N.E., Wise, P.E., Herline, A.J., Muldoon, R.L., Chopp, W.V. \& Schwartz, D.A. 2007, "Carcinoid tumors are 15 times more common in patients with Crohn's disease", Inflammatory bowel diseases, vol. 13, no. 9, pp. 1129-1134.

Westburg, S.P. \& Stone, O.J. 1973, "Multiple cutaneous squamous cell carcinomas during immunosuppressive therapy", Archives of Dermatology, vol. 107 , no. 6 , pp. 893-895.

Weterman, I.T., Biemond, I. \& Pena, A.S. 1990, "Mortality and causes of death in Crohn's disease. Review of 50 years' experience in Leiden University Hospital", Gut, vol. 31, no. 12, pp. 1387-1390.

Winther, K.V., Jess, T., Langholz, E., Munkholm, P. \& Binder, V. 2004, "Longterm risk of cancer in ulcerative colitis: a population-based cohort study from Copenhagen County", Clinical gastroenterology and hepatology : the official clinical practice journal of the American Gastroenterological Association, vol. 2, no. 12 , pp. 1088-1095. 
8. Appendix A:

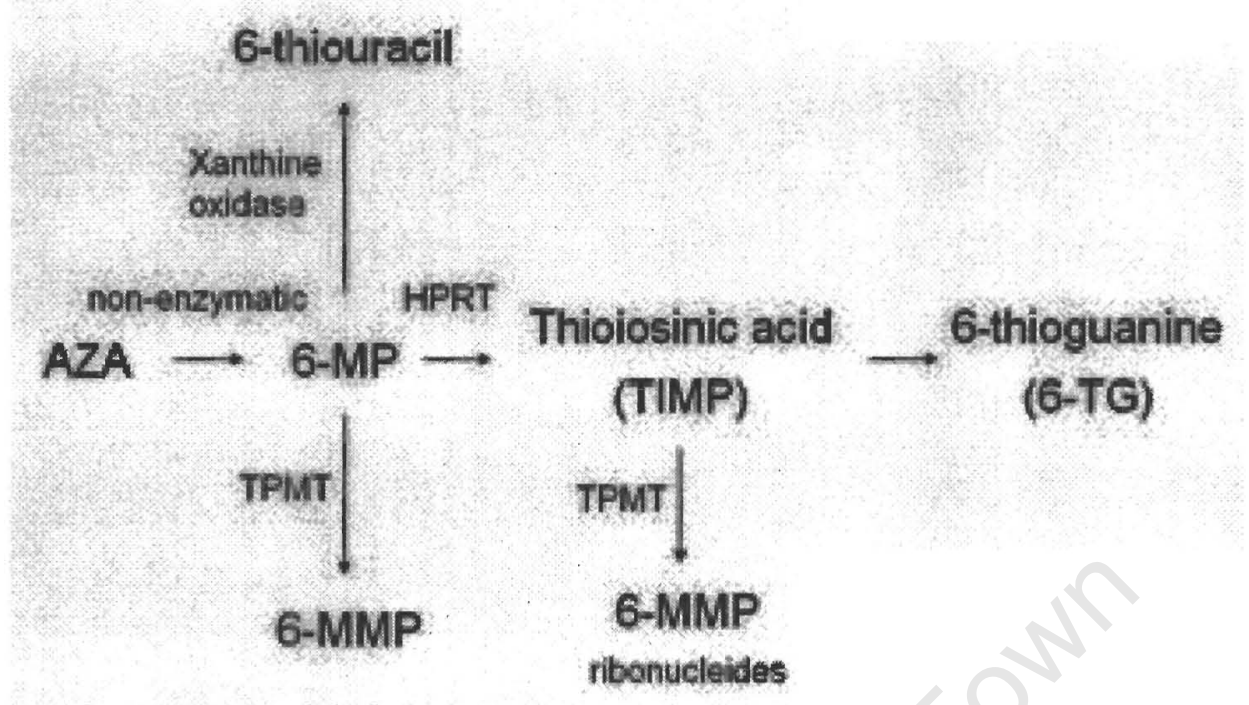

Figure 1: Metabolism of AZA 


\section{Apendix B:}

Model diagnostics

When using Cox's proportional hazards model certain assumptions are made, and thus the model need to be checked to ensure the validity of the model. There are 3 aspects of the model that need checking:

1. Does the model include an appropriate set of explanatory variables, i.e. in the correct form?

This is achieved using the Martingale residuals.

2. Are there any outlying or influential observations that may have exerted a significant leverage on the model, thus altering its predictive capabilities? This aspect is assessed using Schoenfeld and Deviance residuals

3. Is the proportional hazards assumption (that the model is independent of time, and is constant over time) valid and upheld?

This is tested using the Schoenfeld and Score Residuals, and the $\log -\log$ plots.

4. The overall fit and accuracy of the model.

This is tested using the Cox-Snell Residuals and the deviance Residuals.

The model was tested for these assumptions for all the variables; however data is shown for the variable treatment. 


\subsection{Treatment}

8.1.1. Cox-Snell residuals

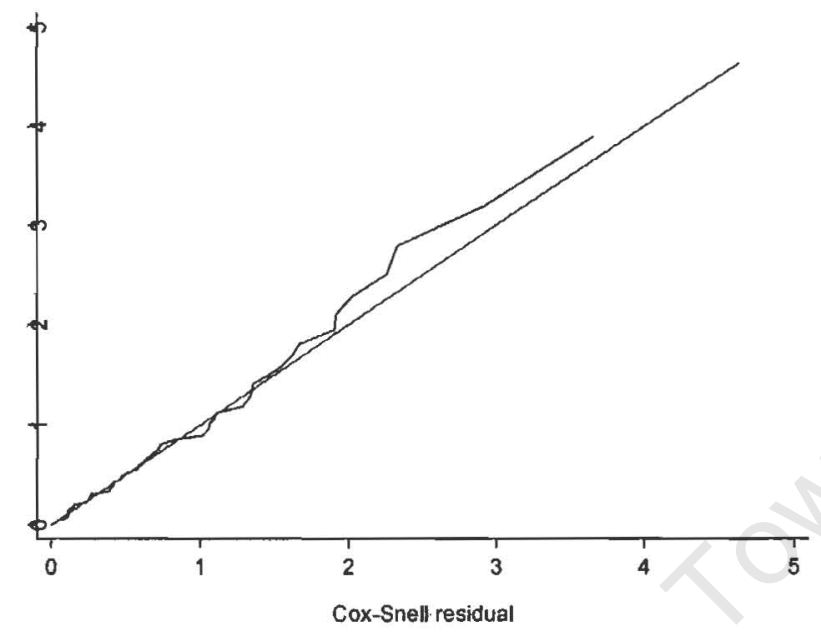

Figure 1: Cox-Snell residuals

The regression line does not deviate from and is virtually parallel to the reference line, thus the Cox model using the Cox-Snell residuals provides a good fit for the data. 
8.1.2. Martingale residuals

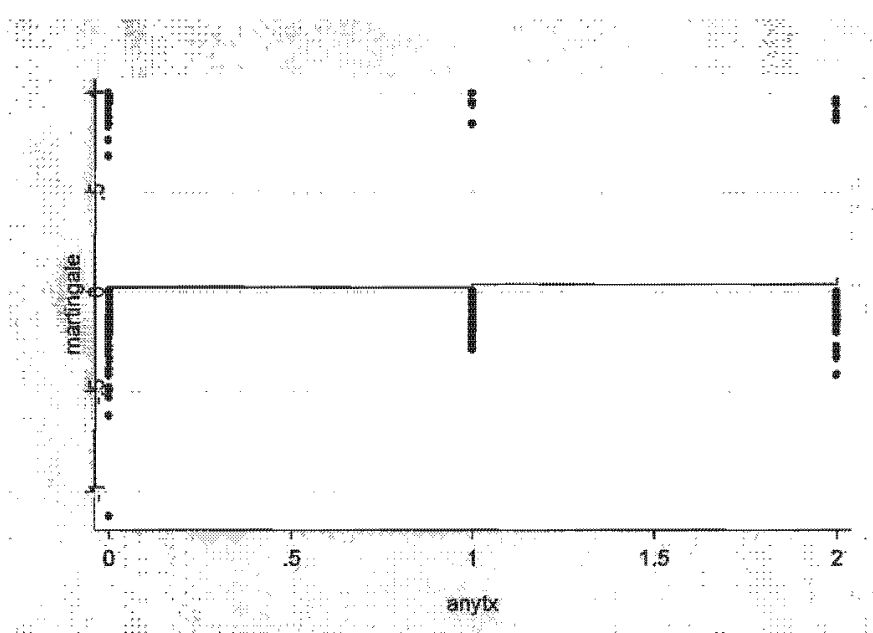

Figure 2: Martingale residuals

Using the Martingale residuals to assess the functional form of the model, the above plot shows a lowess smooth of the residuals plotted against the variable treatment, and the plot is linear. This indicates that the variable treatment is in a correct functional form for inclusion in the model.

\subsubsection{Deviance residuals}

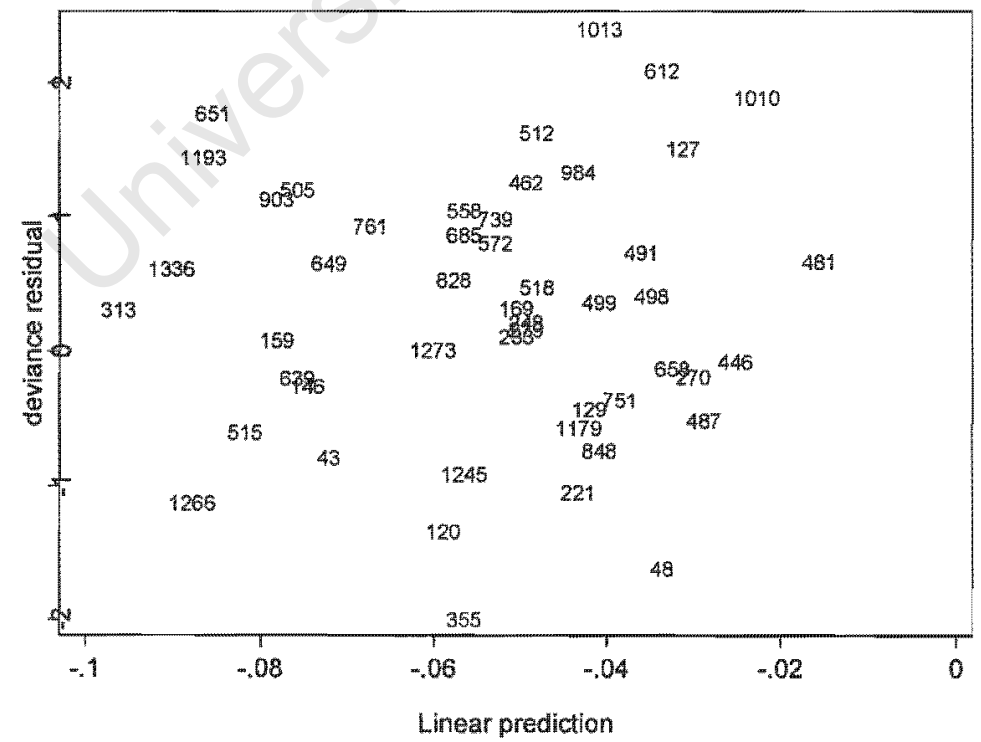

Figure 3: Deviance residuals 
The deviance residuals represent a random scatter around zero, which shows that the model is accurate, and there were no significant outlying data that could have had a significant leverage on the model.

\subsubsection{Proportional hazards assumption}

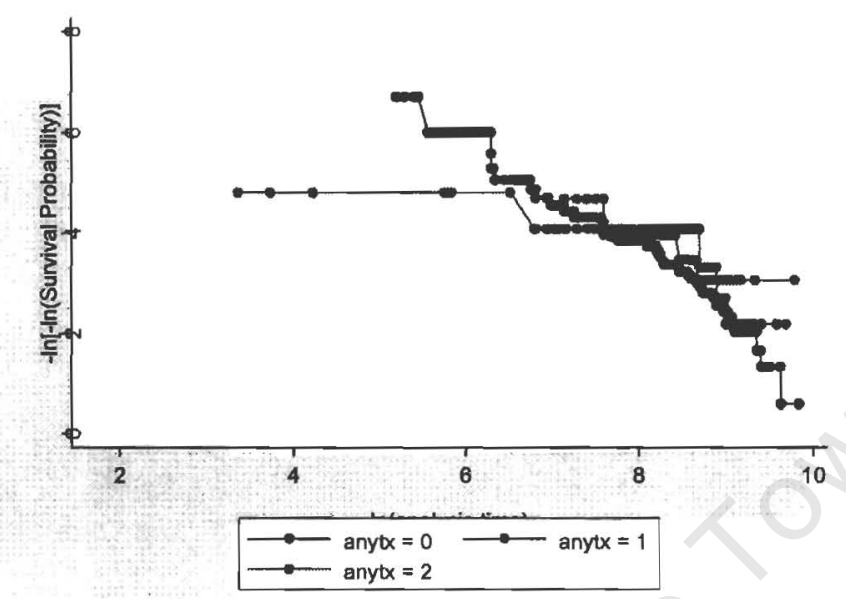

Figure 4a: The log-log plot

The proportional hazards assumption is not violated because these curves are essentially parallel to each other.

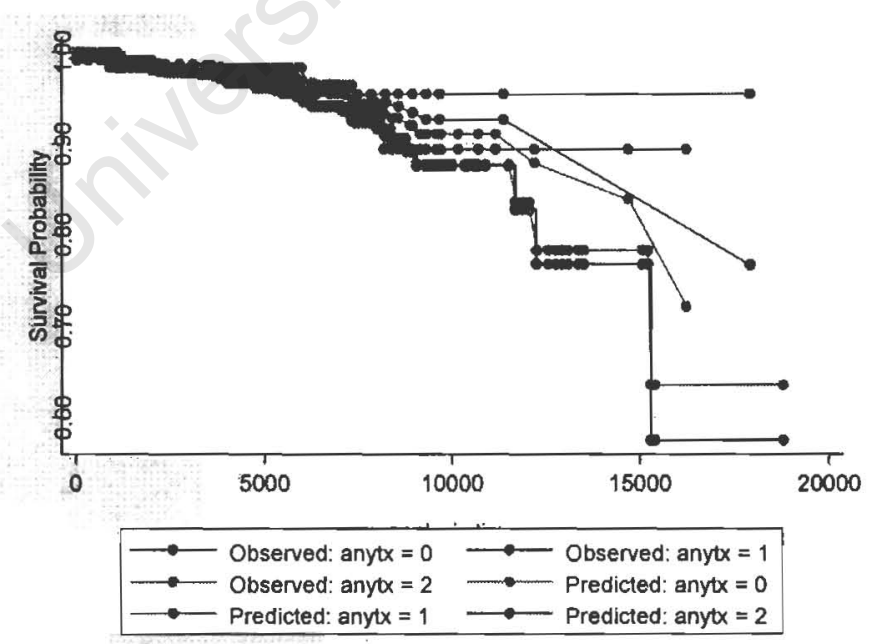

Figure $4 \mathrm{~b}$ : Stcoxkm plots 
The Kaplan-Meier and Cox survival curves coincide thus the proportional hazards assumption is valid.

\subsection{Summary}

Thus overall the multivariate model is compliant with the underlying assumptions of the Cox's proportional hazard function, and therefore the model is a good fit and is valid. 